\title{
Balancing partner preferences for logistics costs and carbon footprint in a horizontal cooperation
}

Citation for published version (APA):

Hacardiaux, T., Defryn, C., Tancrez, J-S., \& Verdonck, L. (2020). Balancing partner preferences for logistics costs and carbon footprint in a horizontal cooperation. Maastricht University, Graduate School of Business and Economics. GSBE Research Memoranda No. 002 https://doi.org/10.26481/umagsb.20002

Document status and date:

Published: 17/02/2020

DOI:

10.26481/umagsb.20002

Document Version:

Publisher's PDF, also known as Version of record

\section{Please check the document version of this publication:}

- A submitted manuscript is the version of the article upon submission and before peer-review. There can be important differences between the submitted version and the official published version of record.

People interested in the research are advised to contact the author for the final version of the publication, or visit the DOI to the publisher's website.

- The final author version and the galley proof are versions of the publication after peer review.

- The final published version features the final layout of the paper including the volume, issue and page numbers.

Link to publication

\footnotetext{
General rights rights.

- You may freely distribute the URL identifying the publication in the public portal. please follow below link for the End User Agreement:

www.umlib.nl/taverne-license

Take down policy

If you believe that this document breaches copyright please contact us at:

repository@maastrichtuniversity.nl

providing details and we will investigate your claim.
}

Copyright and moral rights for the publications made accessible in the public portal are retained by the authors and/or other copyright owners and it is a condition of accessing publications that users recognise and abide by the legal requirements associated with these

- Users may download and print one copy of any publication from the public portal for the purpose of private study or research.

- You may not further distribute the material or use it for any profit-making activity or commercial gain

If the publication is distributed under the terms of Article $25 \mathrm{fa}$ of the Dutch Copyright Act, indicated by the "Taverne" license above, 
Thomas Hacardiaux, Christof Defryn, Jean-Sébastien Tancrez, Lotte Verdonck

\section{Balancing partner} preferences for logistics costs and carbon footprint in a horizontal cooperation

RM/20/002

\section{GSBE}

Maastricht University School of Business and Economics

Graduate School of Business and Economics

\section{P.O Box 616}

NL- 6200 MD Maastricht

The Netherlands 


\title{
Balancing partner preferences for logistics costs and carbon footprint in a horizontal cooperation
}

\author{
Thomas Hacardiaux ${ }^{\mathrm{a}}$ and Christof Defryn ${ }^{\mathrm{b}}$ and Jean-Sébastien Tancrez ${ }^{\mathrm{a}}$ and Lotte \\ Verdonck $^{\mathrm{c}}$
}

${ }^{a}$ CORE - Center for Operations Research and Econometrics, Université catholique de

Louvain

${ }^{\mathrm{b}}$ Department of Quantitative Economics, School of Business and Economics, Maastricht

University

${ }^{\mathrm{c}}$ Research Group Logistics, Hasselt University

\begin{abstract}
Horizontal cooperation in logistics has gathered momentum in the last decade as a way to reach economic as well as environmental benefits. In the literature, these benefits are most often assessed through aggregation of demand and supply chain optimization of the partnership as a whole. However, such an approach ignores the individual preferences of the participating companies and forces them to agree on a unique coalition objective. Companies with different (potentially conflicting) preferences could improve their individual outcome by diverging from this joint solution. To account for companies preferences, we propose an optimization framework that integrates the individual partners' interests directly in a cooperative model. The partners specify their preferences regarding the decrease of logistical costs versus reduced $\mathrm{CO}_{2}$ emissions. Doing so, all stakeholders are more likely to accept the solution, and the long-term viability of the collaboration is improved. First, we formulate a multi-objective, multi-partner location-inventory model. Second, we distinguish two approaches for solving it, each focusing primarily on one of these two dimensions. The result is a set of Pareto-optimal solutions that support the decision and negotiation process. Third, we propose and compare three different approaches to construct a unique solution which is fair and efficient for the coalition. Extensive numerical results not only confirm the potential of collaboration but, more importantly, also reveal valuable managerial insights on the effect of dissimilarities between partners with respect to size, geographical overlap and operational preferences.
\end{abstract}

\section{KEYWORDS}

Horizontal Collaboration, Individual Partners' Preferences, $\mathrm{CO}_{2}$ Emissions, Location-Inventory Model, Multi-Objective Optimisation

Corresponding author. Address: Université catholique de Louvain, Chaussée de Binche, 151, 7000 Mons, Belgium. Tel.: +32 65323 513. ORCID identifier: 0000-0003-4406-1676 


\section{Research context and motivation}

To be competitive in today's demanding markets, it is no longer sufficient to operate at minimum cost (Saad, Rahim, \& Fernando, 2016). Companies are under pressure to also ensure high customer service levels and to account for the growing awareness with respect to environmental sustainability. Encouraged by public incentives and the emergence of carbon taxes, more and more companies integrate emissions targets into all levels of decision-making (Hovelaque \& Bironneau, 2015). The low average vehicle loading rates - currently between $57 \%$ and $68 \%$ in EU-28 countries (Creemers, Woumans, Boute, \& Beliën, 2017; Vargas, Patel, \& Patel, 2018) — show huge potential for improving the sustainability of logistical networks. At the same time, maintaining high delivery frequencies is crucial to remain competitive.

A promising avenue to improve the efficiency as well as the sustainability of the logistical operations is to engage in a collaboration. In this paper, the focus is on horizontal cooperation, which is defined as "multiple companies (potentially competitors), operating at the same level of the supply chain, that join forces with the aim of improving their overall efficiency" (Cruijssen, 2006). Through active sharing of vehicles and facilities, companies can achieve substantial economies of scale. This leads to more efficient vehicle loading rates and a reduction in total kilometres driven, which positively impacts the operational costs as well as the carbon footprint of the collaborating companies (Hacardiaux \& Tancrez, 2019).

A key challenge when modelling and analyzing collaborative environments is that companies remain independent entities with different (potentially conflicting) preferences regarding the characteristics of the logistical network, and with different sizes (thus potentially different influences in the decision process). This challenge is most often circumvented in the literature with two premises: focusing on the improvement in one dimension and considering the coalition as a unique deciding entity. Existing research typically relies on the assumption that all partners agree on a unique objective. Mostly, only the reduction of total logistics costs is considered. Furthermore, customer demands and the preferences of the collaborating partners are aggregated and, doing so, the identity and independence of the partnering companies are ignored (Defryn, Sörensen, \& Dullaert, 2019). Consequently, an optimal solution at the coalition level can be sub-optimal at the individual partner level. This discrepancy creates an incentive for the partners to behave opportunistically and diverge from the proposed 
solution to improve their individual outcome. This potential mismatch between individual partner and coalition objectives jeopardizes the long-term stability, and thus success, of the collaboration.

In this paper, we investigate the design of a cooperative supply network that explicitly accounts for differences in the individual preferences with respect to costs and $\mathrm{CO}_{2}$ emissions reduction, and the influence weight of each partner. To the best of our knowledge, we are the first to analyze such a problem within the context of collaborative logistics. The result is a multi-objective optimization framework that integrates the individual partner preferences, in order to find a solution which is fair and efficient for the coalition. We introduce and compare five different approaches to find such a solution. The first two generate a set of Pareto-optimal solutions that can support the negotiation and decision-making process. The other three approaches help companies to highlight a unique solution based on predefined criteria. To support the presentation and show the working of our framework, it is applied and validated on a multi-objective location-inventory problem. Extensive computational experiments allow us to derive managerial insights for strategic and tactical decision support, including partner selection.

The remainder of the paper is structured as follows. Section 2 contains a literature review and positions the contribution of our paper. In Section 3, the problem setting and the multi-objective and multi-partner collaborative location-inventory model are presented. The first two multi-objective solution approaches that rely on the construction of a Pareto frontier are discussed in Section 4. The other three approaches, aimed at finding a unique solution, are introduced in Section 5. In Section 6, experimental results are presented and relevant managerial insights are derived. Finally, Section 7 concludes our paper and presents ideas for future research.

\section{Related literature}

Due to its practical importance and promising benefits, collaboration in logistics has attracted the interest of the research community over the last decade. Existing studies mainly focus on collaborative transport or distribution systems, where the main motivation for companies to cooperate is an increased efficiency of the vehicle fleet operations and thus a lower logistical cost (Gansterer \& Hartl, 2018; Verdonck, 2017). 
Despite the potential environmental and economical benefits, the sharing of distribution centers or joint inventory management policies have not received large attention from the research community. While location-inventory problems receive increasing academic attention (Daskin \& Maass, 2019; Farahani, Rashidi Bajgan, Fahimnia, \& Kaviani, 2015; Melo, Nickel, \& Saldanha-Da-Gama, 2009), their application in a horizontal cooperation context is novel. Verdonck, Beullens, Caris, Ramaekers, and Janssens (2016) analyze the benefits of cooperative facility location in a horizontal carrier cooperation. Solving the joint location-allocation problem leads to an average reduction in facility opening and distribution costs of 9.1\%. Tang, Lehuédé, and Péton (2016) determine optimal locations for regional distribution centers in a collaborative distribution network. Makaci, Reaidy, Evrard-Samuel, Botta-Genoulaz, and Monteiro (2017) empirically study the sharing of warehouses among different companies to identify, among others, the KPIs and uncertainty sources. Hacardiaux and Tancrez (2018) present a location-inventory model and demonstrate average savings around $22 \%$ in terms of facility opening, transportation, cycle inventory, ordering and safety stock costs when setting up a collaboration. A limited number of papers consider carbon footprint reductions associated with the collaborative location-inventory model. Hacardiaux and Tancrez (2019) analyze the impact of several market and partner characteristics (e.g. vehicle capacity, facility opening cost, inventory holding cost, demand variability) on the reduction of cost and $\mathrm{CO}_{2}$ emissions when collaborating. Stellingwerf, Laporte, Cruijssen, Kanellopoulos, and Bloemhof (2018) analyze the economic and environmental benefits of joint route planning and vendor-managed inventory in the context of collaborative food logistics. Results show significant savings in costs, emissions, distance and travel time, and demonstrate the advantages of vendor-managed inventory in the case under study. Ouhader and El Kyal (2017) propose a multiobjective optimization model, including both facility location and routing decisions, that maximizes costs reduction and job creation subject to a constraint on $\mathrm{CO}_{2}$ emissions. Unlike the work presented in this paper, existing contributions focus exclusively on coalition objectives and the individual preferences of partners are ignored.

Despite its inherent multi-objective nature, horizontal logistics collaboration has mainly been studied from a single-objective perspective in the literature (Defryn et al., 2019). Typically, the collaborative scenario is simulated by aggregating the customers' demand of the different partners, and a single-objective optimization model 
is then solved at the level of the coalition. For the cooperation to be viable, ensuring significant collaborative savings in the long run, however, the individual partner preferences need to be taken into account. A growing body of research exists on multiobjective optimization in various logistics domains. A general overview of relevant literature can be found in Ehrgott (2005), Caramia and Dell'Olmo (2008) and Deb (2014). More specifically, multi-objective applications have been developed for vehicle routing problems (Jozefowiez, Semet, \& Talbi, 2008), facility location problems (Farahani, SteadieSeifi, \& Asgari, 2010) and inventory management (Tsou, 2008). The consideration of multiple objectives in a horizontal cooperation context, however, is a novel research domain. Kimms and Kozeletskyi (2017) develop a multi-objective optimization model for the travelling salesman problem (TSP) with horizontal cooperation. Their goal is to simultaneously minimize travelling costs and maximize the partner utility consequential to order assignment. In line with Kimms and Kozeletskyi (2017), Defryn and Sörensen (2018) solve a multi-objective collaborative TSP aimed at minimizing both the total distance travelled and the customer time window violations. Wang et al. (2018) present a vehicle routing model which minimizes both the operating costs and the number of vehicles in the context of collaborative customer and vehicle sharing. Soysal, Bloemhof-Ruwaard, Haijema, and van der Vorst (2018) model an inventory routing problem analyzing collaborative benefits in terms of multiple objectives, i.e., emissions, driving time and total logistics cost. While each of the papers described above considers multiple objectives on the coalition level, none of them account for individual partner preferences.

To the best of our knowledge, Defryn et al. (2019) are the only to describe and investigate the inclusion of individual partners preferences in collaborative logistical planning. In their paper, they propose a framework that allows for a difference in individual partner preferences while assuring maximal synergy creation through collaboration. Our research work differs from theirs by developing a multi-objective framework both at the coalition and at the individual partner level, accounting for preferences in both costs and $\mathrm{CO}_{2}$ emissions reductions, and accounting for the individual partners' influence on the collaboration. Consequently, in this paper, there is no need for coalition partners to agree on a single coalition objective, contrary to the assumptions made by Defryn et al. (2019). Furthermore, our methodology is tested and validated on a collaborative location-inventory problem aiming to minimize both 
the total logistical cost and the transportation $\mathrm{CO}_{2}$ emissions. Finally, we consider an a priori stated preference articulation with respect to the effect of the collaboration on both objectives. In other words, we analyze the current stand-alone situation for each individual partner to state their preferences in advance. Again, this approach differs from Defryn et al. (2019), in which an a posteriori preference articulation is assumed.

Based on our literature review, we conclude that multi-objective research in horizontal logistics cooperation is scarce. Moreover, the focus is on routing or distribution environments, and only the coalition level is typically considered. Since collaborating companies remain independent entities with potentially conflicting goals, there is an urgent need for more multi-objective, multi-partner models that can account for the individuality of the partners and their preferences.

\section{The multi-objective collaborative location-inventory problem}

In this section, we formally introduce the multi-objective collaborative supply chain network problem. We then formulate both objectives, the minimization of logistics costs and the minimization of $\mathrm{CO}_{2}$ emissions, and finally we present our multi-objective collaborative location-inventory model.

\subsection{Problem definition}

We are given a set of companies wishing to engage in a horizontal collaboration. Each company produces one specific product in their own central plant. As illustrated in Figure 1.a, each company currently has its own (set of) distribution centers (DCs), from where they distribute their product to a group of retailers. We assume that each individual company has independently optimized its distribution network given its preferences regarding costs and $\mathrm{CO}_{2}$ emissions. Each company has opened an optimal number of DCs, chosen their location and allocated the retailers. Cycle inventory is also considered, in particular choosing the right shipment sizes for each transport. To satisfy the uncertain demand during the lead time (which is proportional to the traveled distance) safety stocks are kept at every DC.

Motivated by potential reductions in logistics costs and $\mathrm{CO}_{2}$ emissions, the companies consider setting up a joint supply network in which they share their DCs and vehicles, as illustrated in Figure 1.b. The following advantages can be expected (Hac- 


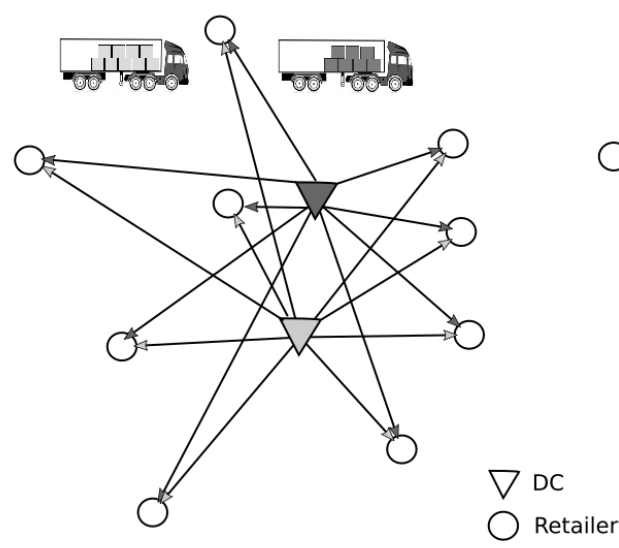

(a) Stand-alone
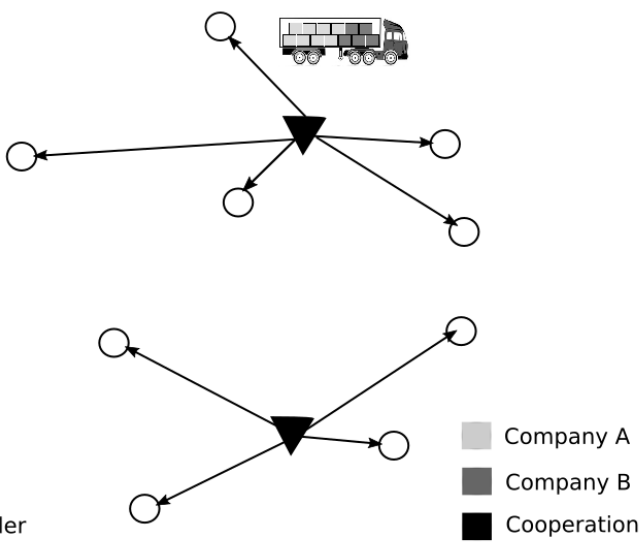

(b) Cooperative

Figure 1.: Illustration of the delivery networks of two independent stand-alone companies (a), and of the joint delivery network of these companies when they are cooperating (b).

ardiaux \& Tancrez, 2019):

- As DCs are shared by the cooperating companies, the total number of DCs is likely to reduce, while each company's product will likely be delivered from more DCs.

- The vehicle loading rates will improve due to the bundling of goods from multiple companies for a shared customer.

- The total distance travelled will decrease for two reasons: retailers are delivered from a potentially closer DC, and the improvement of the loading rate will reduce the number of vehicles travelling (per time period).

Although products from different companies are stored in the same facilities, companies keep their own cycle inventory and safety stock. We asssume direct deliveries and single sourcing, meaning that all the products delivered to a specific retailer come from a single DC, even if these products originate from different partners.

\subsection{Logistics costs and $\mathrm{CO}_{2}$ emissions}

The goal of the coalition is to design a supply chain network that balances the interests of all partners, relative to their two objectives: minimizing the logistics costs and the $\mathrm{CO}_{2}$ emissions. In this section, we formulate the costs and emissions of an individual partner in the coalition (using the mathematical notations listed in Table 1). 
Each individual partner aims to minimize its own share of costs and emissions in the coalition. As detailed below, to share the total logistics costs as well as the total $\mathrm{CO}_{2}$ emissions of the cooperation among partners, we apply proportional rules based on the quantity of products shipped by each partner. In practice, proportional allocation methods are most commonly used due to their simplicity and the fact that they facilitate communication among partners (Guajardo, 2018).

Table 1.: Overview of mathematical notations.

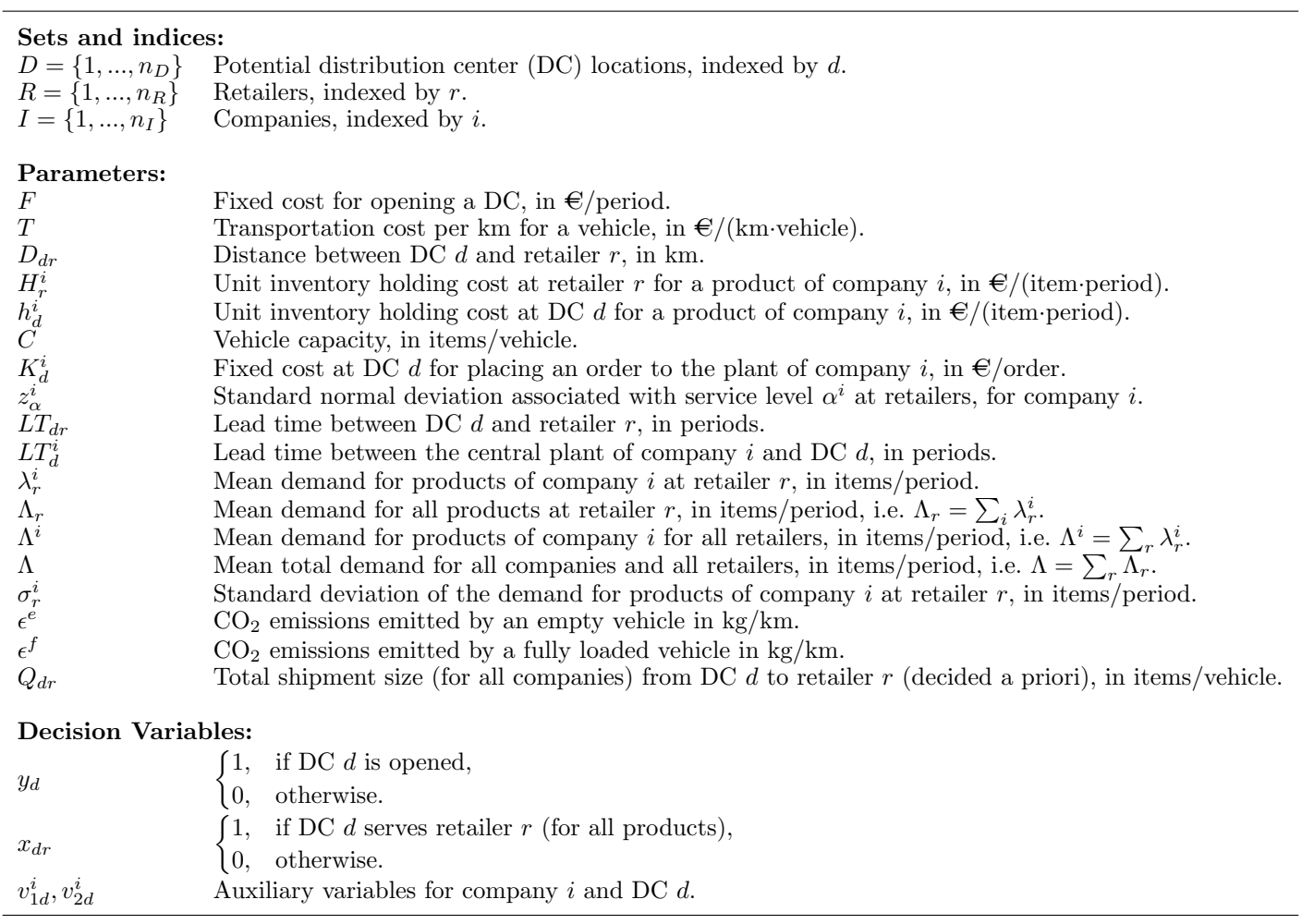

\subsubsection{Objective 1: Minimizing logistics costs}

The logistics costs comprise of the facility opening costs, the transportation costs and the inventory costs. To share the facility costs, a proportional volume-based rule is used such that each partner pays for the fraction of the DC it is storing its products in. Regarding the transportation costs, we use a separate deliveries weighted allocation rule, where, in a similar manner, each partner pays for each vehicle proportionally to the volume its products occupy in it (Frisk, Göthe-Lundgren, Jörnsten, \& Rönnqvist, 2010). The transportation cost allocation is thus different for each retailer $\left(\frac{\lambda_{r}^{i}}{\Lambda_{r}}\right)$. Finally, as each company has its own cycle inventory and safety stock, the inventory costs can 
be directly allocated to a specific partner. The share of the logistics costs for a partner $i$ in the cooperation can thus be expressed as follows.

$$
\begin{aligned}
\frac{\Lambda^{i}}{\Lambda} \sum_{d} F y_{d} & +\sum_{r} \frac{\lambda_{r}^{i}}{\Lambda_{r}} \sum_{d} T D_{d r} \frac{\Lambda_{r}}{Q_{d r}} x_{d r}+\sum_{d, r} H_{r}^{i} \frac{Q_{d r}}{2} \frac{\lambda_{r}^{i}}{\Lambda_{r}} x_{d r}+\sum_{d} \sqrt{2 K_{d}^{i} h_{d}^{i} \lambda_{r}^{i}} x_{d r} \\
& +\sum_{d} h_{d}^{i} z_{\alpha}^{i} \sqrt{L T_{d}^{i}} \sqrt{\sum_{r}\left(\sigma_{r}^{i}\right)^{2} x_{d r}}+\sum_{d, r} H_{r}^{i} z_{\alpha}^{i} \sigma_{r}^{i} \sqrt{L T_{d r}} x_{d r}
\end{aligned}
$$

The terms of equation (1) represent, for company $i$, its share of facility opening costs, its share of transportation costs $\left(\Lambda_{r} / Q_{d r}\right.$ gives the number of shipments per period to a retailer $r$ ), its cycle inventory costs at retailers, its cycle inventory and ordering costs at DCs (assuming an EOQ inventory structure), its safety stock costs at DCs and its safety stock costs at retailers (to reach service level $\alpha$ ).

\subsubsection{Objective 2: Minimizing $\mathrm{CO}_{2}$ emissions}

To account for the $\mathrm{CO}_{2}$ emissions, we focus on transportation and use the formula proposed by Pan, Ballot, and Fontane (2013), which is commonly accepted in the literature (Danloup et al., 2015; Moutaoukil, Neubert, \& Derrouiche, 2015; Ouhader \& El Kyal, 2017). This formula also has the advantage of accounting for the vehicle loading rate, which is an important factor of improvement when cooperating. To allocate the $\mathrm{CO}_{2}$ emissions among partners, we apply the polluter-pays principle (Kellner \& Otto, 2012). $\mathrm{CO}_{2}$ emissions are divided proportionally to the usage of the vehicles (it is also a volume-based rule, $\frac{\lambda_{r}^{i}}{\Lambda_{r}}$ ). This method for the allocation of emissions is frequently applied by practitioners as it is efficient and easy to understand (Leenders, Velázquez-Martínez, \& Fransoo, 2017). The share of $\mathrm{CO}_{2}$ emissions produced by a partner $i$ in the collaboration can be expressed as follows:

$$
\sum_{r} \frac{\lambda_{r}^{i}}{\Lambda_{r}} \sum_{d}\left[\epsilon^{e} \frac{\Lambda_{r}}{Q_{d r}}+\left(\epsilon^{f}-\epsilon^{e}\right) \frac{\Lambda_{r}}{C}\right] D_{d r} x_{d r}
$$

The share of $\mathrm{CO}_{2}$ emissions for company $i$, due to the deliveries to its retailers, is composed of baseline emissions from an empty vehicle, to which emissions proportional to the vehicle load are added. In the first part of equation (2), the $\mathrm{CO}_{2}$ emissions 
emitted by an empty vehicle per $\mathrm{km}\left(\epsilon^{e v}\right)$ are simply multiplied by the number of trips. Then, the $\mathrm{CO}_{2}$ emissions related to the vehicle load $\left(\epsilon^{f v}-\epsilon^{e v}\right)$ are multiplied by the volume of products expressed in full vehicles. To get the total $\mathrm{CO}_{2}$ emissions of the supply chain, these emissions per km are multiplied by the distance, and summed for all deliveries to retailers.

\subsection{Multi-objective collaborative location-inventory model}

In this section, we present our multi-objective collaborative location-inventory model. Equations (1) and (2) provide two criteria that need to be minimized for each partner in the cooperation, leading to a multi-objective and multi-partner optimization model with $2 n_{I}$ objectives. The model aims to determine the number and locations of the joint DCs, the allocation of the flows, as well as inventory decisions regarding the shipment sizes and the safety stocks. Moreover, the model directly allocates the costs and the $\mathrm{CO}_{2}$ emissions to the specific partners. It is formulated as a conic quadratic mixed integer program, which has the advantage to be solvable by commercial optimization softwares. Similarly to Atamtürk, Berenguer, and Shen (2012) and Hacardiaux and Tancrez (2019), the non-linearity in the logistics costs (see equation (1)) is moved to the constraints using auxiliary variables $v_{1 d}^{i}$ and $v_{2 d}^{i}$. In the final model, the objectives are linear and the constraints are either linear or conic quadratic. Our multi-objective collaborative location-inventory model is formulated as follows. 


$$
\begin{gathered}
\min \frac{\Lambda^{i}}{\Lambda} \sum_{d} F y_{d}+\sum_{r} \frac{\lambda_{r}^{i}}{\Lambda_{r}} \sum_{d} T D_{d r} \frac{\Lambda_{r}}{Q_{d r}} x_{d r}+\sum_{d, r} H_{r}^{i} \frac{Q_{d r}}{2} \frac{\lambda_{r}^{i}}{\Lambda_{r}} x_{d r}+\sum_{d} \sqrt{2 K_{d}^{i} h_{d}^{i}} v_{1 d}^{i} \\
+\sum_{d, r} H_{r}^{i} z_{\alpha}^{i} \sigma_{r}^{i} \sqrt{L T_{d r}} x_{d r}+\sum_{d} h_{d}^{i} z_{\alpha}^{i} \sqrt{L T_{d}^{i}} v_{2 d}^{i} \\
\min \sum_{r} \frac{\lambda_{r}^{i}}{\Lambda_{r}} \sum_{d}\left[\epsilon^{e} \frac{\Lambda_{r}}{Q_{d r}}+\left(\epsilon^{f}-\epsilon^{e}\right) \frac{\Lambda_{r}}{C}\right] D_{d r} x_{d r}
\end{gathered}
$$

s.t.

$$
\begin{array}{lc}
\sum_{r} \lambda_{r}^{i}\left(x_{d r}\right)^{2} \leq\left(v_{1 d}^{i}\right)^{2} & \forall d, i \\
\sum_{r}\left(\sigma_{r}^{i}\right)^{2}\left(x_{d r}\right)^{2} \leq\left(v_{2 d}^{i}\right)^{2} & \forall d, i \\
\sum_{d} x_{d r}=1 & \forall r \\
x_{d r} \leq y_{d} & \forall d, r \\
v_{1 d}^{i}, v_{2 d}^{i} \geq 0 & \forall d, i \\
x_{d r}, y_{d} \in\{0,1\} & \forall d, r
\end{array}
$$

Equations (3) minimize the share of logistics costs of each partner and equations (4) minimize the share of $\mathrm{CO}_{2}$ emissions of each partner in the cooperation $\left(2 n_{I}\right.$ objectives). Constraints (5) and (6) define the auxiliary variables $v_{1 d}^{i}$ and $v_{2 d}^{i}$, giving the model its conic quadratic mixed integer program form (using $x_{d r}=x_{d r}^{2}$ and $y_{d}=$ $\left.y_{d}^{2}\right)$. Constraints (7) ensure that each retailer is assigned to exactly one DC (single sourcing). Constraints (8) ensure that a retailer can be served by a DC only if the latter is opened. Constraints (9) impose non-negativity on the auxiliary variables, while constraints (10) enforce the binary nature of decision variables $x_{d r}$ and $y_{d}$. Note that the shipment size decision, $Q_{d r}$, is not treated as a variable when solving our model, but rather as a parameter. We will show in Section 4 that $Q_{d r}$ can be computed a priori, before solving the model, in a way that depends on the approach used to solve model (3)-(10). 


\section{Multi-objective optimization frameworks}

Our multi-objective collaborative location-inventory model is challenging to solve due to the number of objectives, which is equal to the number of partners in the cooperation times two, $2 n_{I}$. In this way, we could say that the objectives are multiple in two dimensions: the logistics costs vs. the $\mathrm{CO}_{2}$ emissions on one hand, the multiple partners on the other hand. In this section, we present two approaches to solve our multiobjective model, where each approach tackles the problem starting from one of the two dimensions in order to generate a specific Pareto frontier.

Even though only one solution is chosen in practice, generating these Pareto fronts provides useful insights into the trade-off between costs and emissions on the one hand and between the partners interests on the other hand. The cost effect of striving for a particular emissions level (and vice versa) can be analyzed, next to the balance of the partners benefits in various collaborative network solutions. Ultimately, this allows collaborative partners to reflect on their preferences and engage in negotiations on the costs-emissions strategy of the collaboration.

\subsection{Articulation at the coalition level}

In the first approach, we tackle the multi-objective problem by aggregating the individual partners, considering the coalition as a whole. In other words, we look at the problem as if the coalition was one homogeneous decision entity (Hacardiaux \& Tancrez, 2019; Tang et al., 2016; Verdonck et al., 2016). The shares of all partners are added up, leading to two objectives: the total coalition costs and the total coalition emissions. Compared to (3)-(4), $\forall i$ is replaced by $\sum_{i}$ (and the equation is simplified). We obtain the following objectives.

$$
\begin{aligned}
\min \sum_{d} F y_{d}+\sum_{d, r} T D_{d r} & \frac{\Lambda_{r}}{Q_{d r}} x_{d r}+\sum_{d, r, i} H_{r}^{i} \frac{Q_{d r}}{2} \frac{\lambda_{r}^{i}}{\Lambda_{r}} x_{d r}+\sum_{d, i} \sqrt{2 K_{d}^{i} h_{d}^{i}} v_{1 d}^{i} \\
+ & \sum_{d, r, i} H_{r}^{i} z_{\alpha}^{i} \sigma_{r}^{i} \sqrt{L T_{d r}} x_{d r}+\sum_{d, i} h_{d}^{i} z_{\alpha}^{i} \sqrt{L T_{d}^{i}} v_{2 d}^{i}
\end{aligned}
$$




$$
\min \sum_{d, r}\left[\epsilon^{e} \frac{\Lambda_{r}}{Q_{d r}}+\left(\epsilon^{f}-\epsilon^{e}\right) \frac{\Lambda_{r}}{C}\right] D_{d r} x_{d r}
$$

\subsubsection{Weighted sum method}

To tackle the remaining bi-objective model, we apply the weighted sum method, with a varying weight $\beta$, which reflects the relative importance of logistics costs versus $\mathrm{CO}_{2}$ emissions for the cooperation (Kim \& de Weck, 2005; Marler \& Arora, 2010). Both objectives are combined and the following model is obtained.

$$
\begin{gathered}
\min \sum_{d} F y_{d}+\sum_{d, r} T D_{d r} \frac{\Lambda_{r}}{Q_{d r}} x_{d r}+\sum_{d, r, i} H_{r}^{i} \frac{Q_{d r}}{2} \frac{\lambda_{r}^{i}}{\Lambda_{r}} x_{d r}+\sum_{d, i} \sqrt{2 K_{d}^{i} h_{d}^{i}} v_{1 d}^{i} \\
+\sum_{d, r, i} H_{r}^{i} z_{\alpha}^{i} \sigma_{r}^{i} \sqrt{L T_{d r}} x_{d r}+\sum_{d, i} h_{d}^{i} z_{\alpha}^{i} \sqrt{L T_{d}^{i}} v_{2 d}^{i} \\
+\beta \sum_{d, r}\left[\epsilon^{e} \frac{\Lambda_{r}}{Q_{d r}}+\left(\epsilon^{f}-\epsilon^{e}\right) \frac{\Lambda_{r}}{C}\right] D_{d r} x_{d r}
\end{gathered}
$$

s.t.

$$
(5)-(10)
$$

The weight $\beta$ is refered to as the costs-emissions weight, and reveals how important $\mathrm{CO}_{2}$ emissions are compared to logistics costs for the collaboration. A small $\beta$ means that the cooperation is focused on costs, while a large $\beta$ reveals a higher environmental attention. The parameter $\beta$ can be interpreted as the monetary cost of $\mathrm{CO}_{2}$ emissions. It can for example be related to carbon taxes or company reputation. The use of this weight solves the problems of nature and proportionality between both objectives, as they were originally expressed in euros and in kilograms of $\mathrm{CO}_{2}$.

As noted in Section 3.3, the shipment size $Q_{d r}$ can be computed prior to solving the model. Deriving equation (13) with respect to $Q_{d r}$, equaling the resulting expressions to zero, and accounting for the vehicle capacity, we find the following closed-form formula for the shipment size. 


$$
Q_{d r}=\min \left(C, \sqrt{\frac{2\left(T+\beta \epsilon^{e}\right) D_{d r} \Lambda_{r}}{\sum_{i} H_{r}^{i} \lambda_{r}^{i} / \Lambda_{r}}}\right)
$$

Note that, as $\beta$ is part of this equation, the ability to compute $Q_{d r}$ a priori is tied to the use of the weighted sum method. This is the reason why, for our location-inventory model, it is the preferred method to tackle the model with the two objectives (11)-(12).

\subsubsection{Pareto front}

Varying the value of $\beta$ in model (13), the Pareto front balancing costs and $\mathrm{CO}_{2}$ emissions at the coalition level can be computed. Figure 2 (black squares) represents this Pareto front for an illustrative case with two partner companies. The first solution on the left of the frontier is obtained by only minimizing the total logistics $\operatorname{costs}(\beta=0)$. For increasing values of $\beta$, we observe a reduction in $\mathrm{CO}_{2}$ emissions caused at first by changes in the inventory policy. More specifically, the shipment size, and thus the vehicles' loading rate, is progressively increased, reducing the number of shipments and the $\mathrm{CO}_{2}$ emissions, but increasing the inventory costs. Then, the $\mathrm{CO}_{2}$ emissions are further decreased by opening additional DCs, which have a major impact on costs (additional facility opening costs) and $\mathrm{CO}_{2}$ emissions (reduced travelled distances).

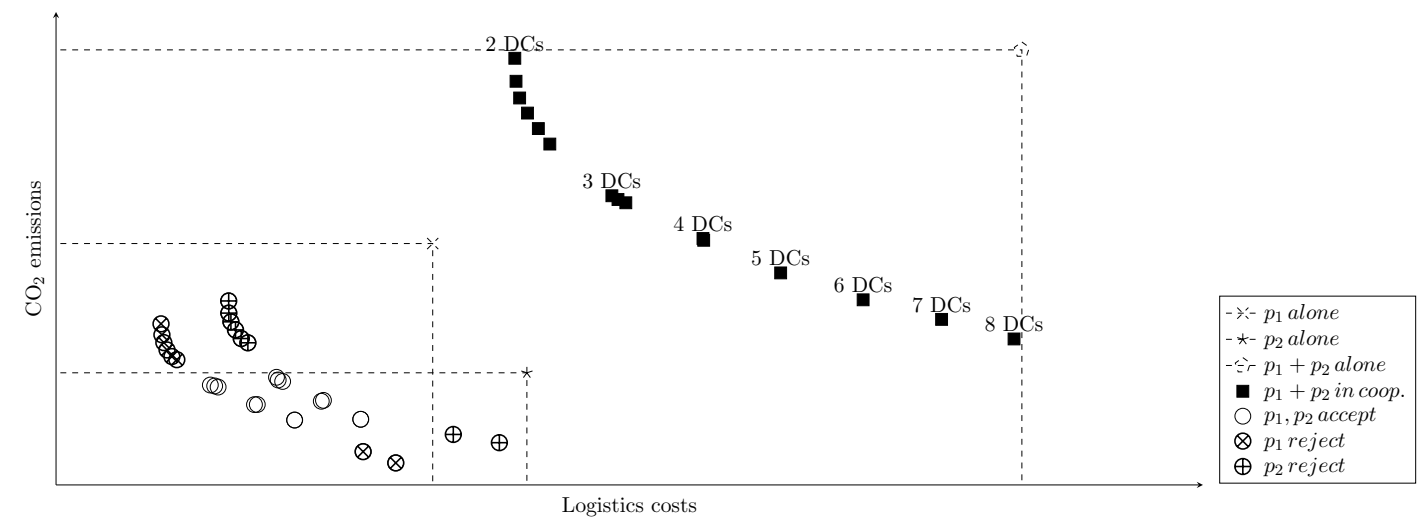

Figure 2.: Balancing the logistics costs and the $\mathrm{CO}_{2}$ emissions on an illustrative case with two companies $p 1$ and $p 2$ : optimal solutions for the stand-alone companies $(\times$ and $\star$ ) and sum of these two (dashed circle); Pareto front for the cooperation, varying $\beta(\mathbf{\square})$; and allocated shares for both companies of each Pareto front solution $(\otimes, \bigoplus$, $\bigcirc)$

For each solution of the Pareto front at the coalition level, the costs and $\mathrm{CO}_{2}$ 
emissions can be shared among the partners using volume-based allocation rules (as described in Section 3.2). For each partner, the resulting trade-off between the costs share and the emissions share is illustrated in Figure 2 (empty circles). This allows to assess the solutions at the individual partner level. In particular, a partner could decide to reject a given solution because it violates rationality principles (Zolezzi \& Rudnick, 2002). Two rationality principles are discussed in the following.

Individual rationality means that a partner will not accept a solution that is worse than its stand-alone situation. In other words, a partner will not accept to enter a cooperation that causes him to increase its costs or its $\mathrm{CO}_{2}$ emissions. Only solutions that dominate all stand-alone solutions will be accepted by all partners. If no such solution exists, we can conclude that the collaboration will not be viable. In Figure 2 , allocated individual shares above or on the right of the stand-alone solutions are deemed unacceptable and crossed. If a cooperative solution is rejected by at least one of the partners, this solution is inaccessible to the other partners even if acceptable for them individually (see crossed solutions $\otimes$ in the acceptable area in Figure 2).

Collective rationality states that the cooperation should create synergy, implying that it should decrease both the logistics costs and $\mathrm{CO}_{2}$ emissions. Solutions in the Pareto front of the cooperation are thus acceptable if their cost is smaller than the sum of the stand-alone costs and correspondingly for the $\mathrm{CO}_{2}$ emissions. In Figure 2, all depicted solutions satisfy those conditions since they are all situated under and on the left of the solution summing the stand-alone cases (dashed circle). Note that multiple Pareto optimal solutions remain and that only one can be implemented (see Section 5).

\subsection{Articulation at the partner level}

In the second approach, we tackle the multi-objective problem starting by the balance between the logistics costs and the $\mathrm{CO}_{2}$ emissions. For each partner $i$ in the coalition, these two objectives are added, accounting for its preferences regarding costs versus emissions using $\beta_{i}$. Similar to the $\beta$ introduced in Section 4.1, $\beta_{i}$ can be interpreted as the monetary cost for company $i$ of emitting one kilogram of $\mathrm{CO}_{2}$, and denotes the importance according to partner $i$ of reducing the $\mathrm{CO}_{2}$ emissions compared to reducing the logistics costs. It is referred to as the individual costs-emissions weight. The resulting sum, which aggregates the direct logistics costs and the indirect costs 
coming from $\mathrm{CO}_{2}$ emissions, is referred to as the augmented cost (and noted $A u g C$ ). Each partner in the coalition aims to minimize its augmented cost, leading to the following objectives.

$$
\begin{aligned}
& \min \frac{\Lambda^{i}}{\Lambda} \sum_{d} F y_{d}+\sum_{d, r} T D_{d r} \frac{\lambda_{r}^{i}}{Q_{d r}} x_{d r}+\sum_{d, r} H_{r}^{i} \frac{Q_{d r}}{2} \frac{\lambda_{r}^{i}}{\Lambda_{r}} x_{d r}+\sum_{d} \sqrt{2 K_{d}^{i} h_{d}^{i}} v_{1 d}^{i} \\
& +\sum_{d, r} H_{r}^{i} z_{\alpha}^{i} \sigma_{r}^{i} \sqrt{L T_{d r}} x_{d r}+\sum_{d} h_{d}^{i} z_{\alpha}^{i} \sqrt{L T_{d}^{i}} v_{2 d}^{i}+\boldsymbol{\beta}^{i} \sum_{d, r}\left[\epsilon^{e} \frac{\lambda_{r}^{i}}{Q_{d r}}+\left(\epsilon^{f}-\epsilon^{e}\right) \frac{\lambda_{r}^{i}}{C}\right] D_{d r} x_{d r} \quad \forall \boldsymbol{i}
\end{aligned}
$$

In our approach, the individual costs-emissions weights $\beta_{i}$ are supposed to be known. They can easily be inferred from the stand-alone situation (before cooperation) as we assume that each company has optimally designed its supply chain according to its individual preferences. Using this concept of revealed preference articulation, it is not necessary to ask the decision-makers to explicitly express their individual preferences and avoids the use of untruthful information (Veldhuizen \& Lamont, 2000).

\subsubsection{Weighted sum method}

In order to solve the remaining multi-objective model, we again apply a weighted sum approach, as in Section 4.1 (Kim \& de Weck, 2005; Marler \& Arora, 2010). This time, the weights $\gamma^{i}$ are used. They are referred to as the partner influence weights, as they reflect the relative influence of each partner in the coalition, i.e. how important the reduction of the augmented cost of company $i$ is compared to the reduction of the augmented cost of its partners. The resulting model is the following.

$$
\begin{aligned}
\min & \sum_{i} \gamma^{i}\left[\frac{\Lambda^{i}}{\Lambda} \sum_{d} F y_{d}+\sum_{d, r} T D_{d r} \frac{\lambda_{r}^{i}}{Q_{d r}} x_{d r}+\sum_{d, r} H_{r}^{i} \frac{Q_{d r}}{2} \frac{\lambda_{r}^{i}}{\Lambda_{r}} x_{d r}+\sum_{d} \sqrt{2 K_{d}^{i} h_{d}^{i}} v_{1 d}^{i}\right. \\
& \left.+\sum_{d, r} H_{r}^{i} z_{\alpha}^{i} \sigma_{r}^{i} \sqrt{L T_{d r}} x_{d r}+\sum_{d} h_{d}^{i} z_{\alpha}^{i} \sqrt{L T_{d}^{i}} v_{2 d}^{i}+\beta^{i} \sum_{d, r}\left[\epsilon^{e} \frac{\lambda_{r}^{i}}{Q_{d r}}+\left(\epsilon^{f}-\epsilon^{e}\right) \frac{\lambda_{r}^{i}}{C}\right] D_{d r} x_{d r}\right]
\end{aligned}
$$

s.t.

(5) $-(10)$ 
As previously noted, the shipment size $Q_{d r}$ can be computed a priori. Deriving equation (16), equaling the resulting expressions to zero, and accounting for the vehicle capacity, we find the following closed-form formula.

$$
Q_{d r}=\min \left(C, \sqrt{\frac{2\left[\sum_{i} \gamma^{i} \lambda_{r}^{i}\left(T+\beta^{i}\right) \epsilon^{e}\right] D_{d r}}{\sum_{i} \gamma^{i} H_{r}^{i} \lambda_{r}^{i} / \Lambda_{r}}}\right)
$$

\subsubsection{Pareto front}

Varying the partner influence weights $\left(\gamma^{i}\right)$, single-objective optimization models can be solved to generate the Pareto front, showing the trade-offs between the companies' augmented costs. Figure 3 shows the Pareto front for an illustrative case with two cooperating companies, where the first company gives priority to costs while the second company has a higher preference for $\mathrm{CO}_{2}$ emissions $\left(\beta^{2}>\beta^{1}\right)$. The first solution on the left of the frontier is obtained by only minimizing the augmented cost of the costfocused partner $\left(\gamma_{1}>0\right.$ and $\left.\gamma_{2}=0\right)$, i.e. supposing that the first company has all the decision power in the cooperation. When the ratio $\gamma_{2} / \gamma_{1}$ increases, the emissionsfocused company gets more power in the decision process. The locations of the DCs will be modified to get closer to its large customers. Moreover, as $\beta^{2}>\beta^{1}$, the cooperation will become more environmentally friendly, and more DCs will be opened to reduce traveled distances. Finally, the last solution on the right of Figure 3 is the one that best accommodates the preferences of the emissions-focused company (with $\gamma_{1}=0$ and $\left.\gamma_{2}>0\right)$.

\section{Identifying unique solutions}

In Section 4, we proposed two approaches to reduce the multi-dimensionality of our model (3)-(10), leading to Pareto fronts that help decision-makers in designing a collaborative supply chain. The Pareto fronts balance the logistics costs and $\mathrm{CO}_{2}$ emissions of the coalition (Section 4.1) or compromise the partners' augmented costs (Section 4.2).

In this section, as a complement to these results, we propose three different approaches to identify a unique solution, that would be considered fair and efficient by every partner. The first two approaches use a value for either $\beta$ or $\gamma_{i}$ in order to generate a unique solution from the models (13) and (16) given in Section 4.1 and 


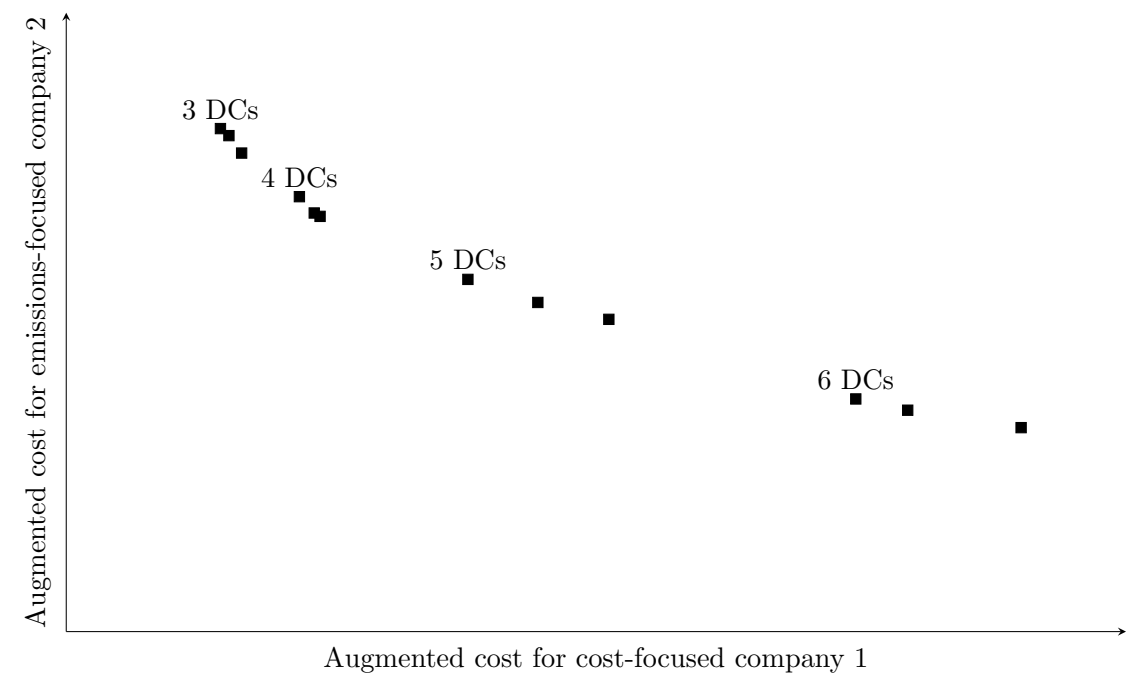

Figure 3.: Pareto front balancing the augmented costs of two cooperating companies (with $\beta^{2}>\beta^{1}$ ).

Section 4.2 , respectively. The third approach aims to find a fair balance between the individual benefits that horizontal cooperation generates for the partners. For each of these three approaches, two methods are suggested, differing in terms of the way $\beta$ and $\gamma_{i}$ are calculated and in the viewpoint on fairness of individual partner benefits, respectively. These six methods are presented in Sections 5.1, 5.2 and 5.3. They can be applied as a complement to the analysis of the Pareto fronts (Section 4) to highlight solutions that are particularly relevant, and serve as a starting point for collaborative negotiations. Moreover, they have the advantage of being less computationally expensive if the decision-makers prefer to bypass the Pareto fronts generation altogether. They can also easily be used with more than two companies while the complexity of the Pareto fronts representation increases with the number of partners. Finally, in the context of a company looking to select a partner, unique solutions (rather than Pareto fronts) make it easier to compare potential partners and assess potential fit and benefits.

\subsection{Costs-emissions weight $\beta$ approach}

In order to determine a unique solution for model (13), without generating the Pareto front, the value of the collaboration's costs-emissions preference weight, $\beta$, has to be fixed. For this, we rely on the known preferences of each partner, $\beta^{i}$, which can be inferred from their stand-alone supply chain (see Section 4.2). In order for the 
cooperation's $\beta$ to be acceptable by all partners, each $\beta^{i}$ is accounted for in proportion to the company's importance. Two methods are presented here, which define this importance based either on the demand volumes of the partners or on their augmented costs. As discussed before, proportional techniques are the most commonly used in practice as they are simple, support communication purposes and do not require a substantial amount of data (Guajardo, 2018).

- Volume weighted $\beta_{V o l}$

In the cooperation literature, allocation and aggregation techniques often rely on demand volumes (Guajardo \& Rönnqvist, 2016). Following this common practice, in this first method, $\beta$ is computed as the weighted average of the partner preferences $\left(\beta^{i}\right)$, weighted by their demand volume, as follows.

$$
\beta_{V o l}=\sum_{i} \beta^{i} \frac{\Lambda^{i}}{\Lambda}
$$

This volume weighted computation naturally favors the largest company, giving its preference a higher importance. This coincides with the research results of Cruijssen, Cools, and Dullaert (2007) stating that larger coalition players are the most powerful partners in practice.

- Augmented cost weighted $\beta_{\text {AugC }}$

Next to demand volumes, stand-alone costs are also often used as a criterion for collaborative aggregation or allocation purposes (Guajardo \& Rönnqvist, 2016). Accordingly, our second method computes $\beta$ as the weighted average of the preferences $\beta^{i}$ weighted by the stand-alone augmented cost. With $C_{S A}^{i}$ being the stand-alone cost of partner $i$ and $E_{S A}^{i}$ its $\mathrm{CO}_{2}$ emissions, the stand-alone augmented cost of partner $i$ can be computed as $A u g C_{S A}^{i}=C_{S A}^{i}+\beta^{i} E_{S A}^{i}$. The cooperation's preference weight $\beta$ can then be formulated as follows.

$$
\beta_{A u g C}=\sum_{i} \beta^{i} \frac{A u g C_{S A}^{i}}{\sum_{j} A u g C_{S A}^{j}}
$$

This augmented cost weighted computation favors companies with a larger standalone augmented cost, thus accounting for both logistics costs and $\mathrm{CO}_{2}$ emissions. 


\subsection{Partner influence weight $\gamma^{i}$ approach}

To find a unique solution using model (16), without generating the Pareto front, the value of every partner's influence weight $\gamma^{i}$ has to be fixed. These weights characterize the influence of the companies on the final cooperative solution. To define them, we rely again on proportional techniques, using the demand volumes or the stand-alone augmented costs, similar to the computation of $\beta$ (Section 5.1).

- Volume weighted $\gamma_{V o l}^{i}$

Demand volumes can be used to reflect the size and negotiation power of a company in the partnership (Cruijssen, Cools, \& Dullaert, 2007). Based on this idea, the influence weight $\gamma^{i}$ of partner $i$ is computed as the ratio of its demand to the total demand of all partners.

$$
\gamma_{V o l}^{i}=\frac{\Lambda^{i}}{\Lambda} \quad \forall i
$$

In this way, a larger company will have more impact on collaborative decisions. Note, however, that this method does not account for the fact that a larger demand volume will typically allow a company to be more efficient, compared to a smaller company. To account for that, the next method is introduced.

- Augmented cost weighted $\gamma_{V o l}^{i}$

In this second method, the augmented cost in the stand-alone case is used to reveal the influence of a partner. The partner influence weights, $\gamma^{i}$, are computed as the ratio of their stand-alone augmented cost to the total augmented cost of all partners.

$$
\gamma_{A u g C}^{i}=\frac{A u g C_{S A}^{i}}{\sum_{k} A u g C_{S A}^{k}} \quad \forall i
$$

Unlike the previous method, using the augmented cost allows to account for the economies of scale that can be achieved through higher volumes. However, to get to the augmented cost, the costs, $\mathrm{CO}_{2}$ emissions and individual costsemissions weights $\left(\beta^{i}\right)$ are more difficult to assess than volumes. 


\subsection{Partners benefits approach}

The two previous approaches are based directly on the multi-objective models proposed in Section 4, balancing costs versus $\mathrm{CO}_{2}$ emissions (Sections 4.1) or balancing the augmented costs of the partners (4.2). The approach presented in this section looks at the benefits that cooperation generates for the partners individually. The relative benefit from cooperating for a partner $i$ is computed as $\left(A u g C_{S A}^{i}-A u g C_{C o o p}^{i}\right) / A u g C_{S A}^{i}$, where $A u g C_{S A}^{i}$ is the stand-alone augmented cost of partner $i$ and $A u g C_{C o o p}^{i}$ is its share of the cooperation's augmented cost. The main motivation for a company to engage in a horizontal cooperation is to reduce its own costs and $\mathrm{CO}_{2}$ emissions, i.e., decrease its individual augmented cost. In practice, a cooperation that leads to vastly different benefits among partners may be considered unfair, at least by those that benefit less. In the same vein, a collaborative supply network that is far from the ideal network for one company will likely result in dissatisfaction and threatens the long-term stability of the collaboration.

Figure 4 displays the relative benefits of each partner in a two company collaboration, for the solutions of the Pareto fronts as computed in Section 4, using articulation at the coalition level (model (13)) or articulation at the partner level (16). We observe a range of potential benefits for both companies. In isolation, the companies would chose very different collaborative networks, i.e., the two extreme points, leading to their ideal benefits. In what follows, we introduce two methods for selecting one solution from these solution sets, in order to guide decision makers. Both methods do not require the Pareto fronts to be known.

- Maximizing the minimal partner benefit, MmBenefit

Our first method aims at maximizing the lowest individual benefit a partner gets from cooperating. It will thus lead to a solution in which the company benefiting the less gets as much as possible, and in which the benefits gotten by the different partners are as similar as possible. In Figure 4, this solution (represented by a triangle) is the one closest to the line with identical benefits for the partners. To find this solution, the following model is solved, maximizing the smallest benefit among partners (with Benefit and $A u g C_{C o o p}^{i}$ being variables and $A u g C_{S A}^{i}$ being a parameter, computed a priori). 


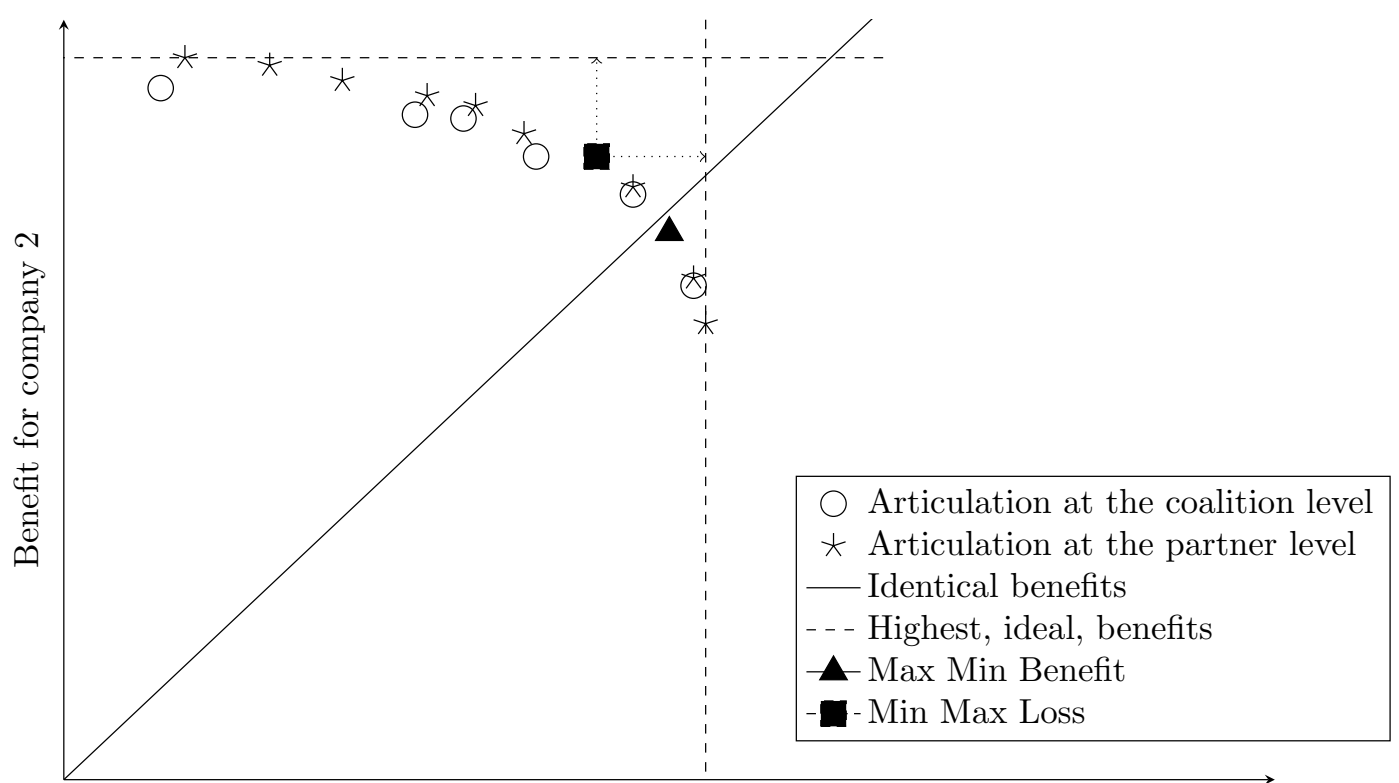

Benefit for company 1

Figure 4.: Relative benefits from cooperation, in augmented costs, that can be achieved by two companies collaborating, for the solutions found applying the articulation at the coalition level and the articulation at the partner level.

$\max$ Benefit

s.t.

$$
\begin{aligned}
& \text { Benefit } \leq \frac{A u g C_{S A}^{i}-A u g C_{\text {Coop }}^{i}}{A u g C_{S A}^{i}} \quad \forall i \\
& \begin{array}{l}
\text { Aug } C_{\text {Coop }}^{i}=\frac{\Lambda^{i}}{\Lambda} \sum_{d} F y_{d}+\sum_{d, r} T D_{d r} \frac{\lambda_{r}^{i}}{Q_{d r}} x_{d r}+\sum_{d, r} H_{r}^{i} \frac{Q_{d r}}{2} \frac{\lambda_{r}^{i}}{\Lambda_{r}} x_{d r} \\
+\sum_{d} \sqrt{2 K_{d}^{i} h_{d}^{i}} v_{1 d}^{i}+\sum_{d, r} H_{r}^{i} z_{\alpha}^{i} \sigma_{r}^{i} \sqrt{L T_{d r}} x_{d r}+\sum_{d} h_{d}^{i} z_{\alpha}^{i} \sqrt{L T_{d}^{i}} v_{2 d}^{i} \\
+\beta^{i} \sum_{d, r}\left[\epsilon^{e} \frac{\lambda_{r}^{i}}{Q_{d r}}+\left(\epsilon^{f}-\epsilon^{e}\right) \frac{\lambda_{r}^{i}}{C}\right] D_{d r} x_{d r} \quad \forall i \\
(5)-(10) \\
\text { Benefit } \geq 0 \\
\text { Aug } C_{\text {Coop }}^{i} \geq 0
\end{array} \quad \forall i
\end{aligned}
$$

Since this method leads to similar benefits among partners, it supports accep- 
tance among partners and is in line with the premise of the equal profit method (Frisk et al., 2010). As such, it may be helpful in the early phases of a growing horizontal cooperation for communication and negotiation purposes (Verdonck et al., 2016). However, especially if partner characteristics and/or contributions are very dissimilar, it can be questioned whether an equal distribution of the benefits is desirable. Moreover, given its strive for more equal partner benefits, this method generally affects the average savings of the solution in a negative way. These specific cases will be numerically explored in detail in Section 6 .

- Minimizing the maximal partner loss, mMLoss

This last method is based on the statement that partners ultimately desire cooperative solutions which are as close as possible to their ideal cooperative solution from an individual perspective, i.e. the solution that maximizes their own benefit. The method thus aims at minimizing the maximum loss (dissatisfaction) of each partner accounting for the cooperative solution that would be chosen individually, similarly to the idea behind the Nucleolus method (Schmeidler, 1969). The solution that company $i$ would select if it could decide alone for the cooperation (with an augmented cost noted $A u g C_{\text {Coop }}^{i *}$ ) is computed a priori, solving model (16) (Section 4.2) with influence weight $\gamma^{i}=1$ for company $i$, and zero weights for other companies. The corresponding solutions for all partners are highlighted with the dashed lines in Figure 4. Note that these solutions could be unacceptable as they might not comply with the individual rationality principle. Accounting for this, the method finds the solution that minimizes the maximum difference in benefits with these previously computed solutions, as illustrated by the black square in Figure 4. The following model is solved, with Loss and $A u g C_{C o o p}^{i}$ being variables. 
s.t.

$$
\begin{aligned}
& \text { Loss } \geq \frac{A u g C_{\text {Coop }}^{i}-A u g C_{\text {Coop }}^{i *}}{A u g C_{S A}^{i}} \quad \forall i \\
& \text { AugC Coop }=\frac{\Lambda^{i}}{\Lambda} \sum_{d} F y_{d}+\sum_{d, r} T D_{d r} \frac{\lambda_{r}^{i}}{Q_{d r}} x_{d r}+\sum_{d, r} H_{r}^{i} \frac{Q_{d r}}{2} \frac{\lambda_{r}^{i}}{\Lambda_{r}} x_{d r} \\
& +\sum_{d} \sqrt{2 K_{d}^{i} h_{d}^{i}} v_{1 d}^{i}+\sum_{d, r} H_{r}^{i} z_{\alpha}^{i} \sigma_{r}^{i} \sqrt{L T_{d r}} x_{d r}+\sum_{d} h_{d}^{i} z_{\alpha}^{i} \sqrt{L T_{d}^{i}} v_{2 d}^{i} \\
& +\beta^{i} \sum_{d, r}\left[\epsilon^{e} \frac{\lambda_{r}^{i}}{Q_{d r}}+\left(\epsilon^{f}-\epsilon^{e}\right) \frac{\lambda_{r}^{i}}{C}\right] D_{d r} x_{d r} \quad \forall i
\end{aligned}
$$$$
(5)-(10)
$$$$
\text { Loss } \geq 0
$$$$
A u g C_{\text {Coop }}^{i} \geq 0 \quad \forall i
$$

As the difference between the individually desirable solution and the cooperative solution is minimized, this approach will reduce the partners' willingness to leave the cooperation, and thus supports the long-term stability of the cooperation.

\section{Computational Experiments}

In this section, we present and discuss our experimental results in order to compare and validate all the approaches introduced in the previous sections. First, we introduce the experimental setting in Section 6.1. In Section 6.2, we discuss the working of both approaches presented in Section 4, that lead to Pareto fronts, relying on preference articulation at the coalition and at the partner level. In Section 6.3, we analyze the three approaches for finding unique solutions presented in Section 5. Finally, Sections 6.4 and 6.5 study collaborations among companies that are dissimilar in size (and therefore power) or have a different geographical demand distribution. 


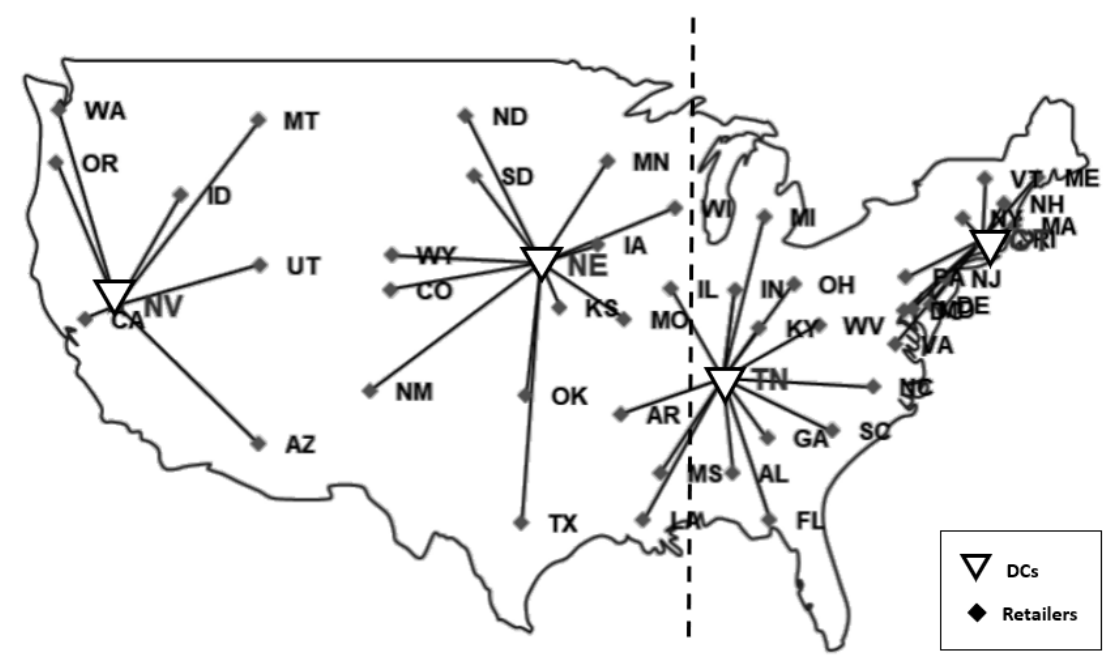

Figure 5.: Joint supply network for two collaborating companies with similar demand structures and costs-emissions preferences $\left(\beta_{1}=\beta_{2}=3\right)$, using the volume weighted $\beta_{V o l}$ method (equation (18)). The dashed line distinguishes the eastern and the western cities (see Section 6.5).

\subsection{Experimental Setting}

In our experiments, we focus on a cooperation between two companies, operating in the U.S. market. The retailer's locations are taken from the 49-node data set by Daskin (2011), which includes the 48 continental U.S. state capitals plus Washington DC. This data set is commonly used in the facility location literature (Jeon, Snyder, \& Shen, 2006; Santiváñez \& Carlo, 2018). All retailers' locations are considered to be the possible locations for the DCs. This assumption is common and well-accepted in the facility location literature (see e.g. Atamtürk et al. (2012); Shen, Coullard, and Daskin (2003)). The 49 cities and the joint supply network for a specific collaboration are illustrated in Figure 5.

The parameter values, reflecting the characteristics of the two cooperating companies, are detailed in Table 2. These parameter values are used for both companies in all our experiments except for the companies' size and geographical distribution which differ in Sections 6.4 and 6.5 (i.e. demands $\lambda_{r}^{i}$ differ). In order to highlight relevant insights, we assume that the companies share similar cost structures, but do not necessarily share the same costs versus emissions preferences $\left(\beta_{i}=1,3\right.$ or 5 depending on the experiments). Following Atamtürk et al. (2012); Schuster Puga, Minner, and Tancrez (2019), we use the city's population size divided by 1000 (noted $\pi_{r}$ ) as the baseline for the retailer's daily demand. To allow for variance in the dataset, a devia- 
tion of $25 \%$ is considered. For each company, the expected daily demand at a retailer, $\lambda_{r}^{i}$, is randomly generated within the intervals $\left[0.75 \pi_{r} ; 1.25 \pi_{r}\right]$. The standard deviation of the demand is found applying a CV of 0.5 (normal distributions are assumed). The service level is set at $97.5 \%$. A transportation cost of $1 € / \mathrm{km}$ is considered per vehicle. The vehicle capacity is fixed at a maximum of 2500 items per vehicle. The use of a DC involves a facility opening cost of $1000 €$. The order cost and the holding costs are $500 €$ per order and $0.05 €$ per item respectively (as in Atamtürk et al. (2012); Schuster Puga et al. (2019)). Lead times between DCs and retailers are directly proportional to the distance (assuming an average speed of $50 \mathrm{~km} / \mathrm{h}$ ). The order lead time from all DCs to all plants is fixed to the average lead time from all potential DCs to all retailers. The $\mathrm{CO}_{2}$ emissions emitted by a vehicle are set to $0.857 \mathrm{~kg} / \mathrm{km}$ for an empty vehicle $\left(\epsilon^{e}\right)$ and $1.209 \mathrm{~kg} / \mathrm{km}$ for a full vehicle $\left(\epsilon^{f}\right)$. These values are obtained applying the formula proposed by Hickman, Hassel, Joumard, Samaras, and Sorenson (1999), considering a heavy-duty vehicle (maximum load of 25 tons) driving at a speed of $50 \mathrm{~km} / \mathrm{h}$, and ignoring the gradient of the road (Pan et al., 2013). Models are implemented in CPLEX and run on a $3.2 \mathrm{GHz}$ computer with $8 \mathrm{~GB}$ of RAM. Problems are solved to optimality both for the stand-alone and the cooperation cases.

Table 2.: Parameters values for the numerical experiments.

\begin{tabular}{ll}
\hline$\lambda_{r}^{i}$ & {$\left[0.75 \pi_{r} ; 1.25 \pi_{r}\right]$ items/day } \\
$C V$ & 0.5 \\
$\alpha^{i}$ & $97.5 \%$ \\
$z_{\alpha}^{i}$ & 1.96 \\
$T$ & $1 € / \mathrm{km}$ \\
$C$ & 2500 items \\
$F_{d}$ & $1000 € /$ day \\
$K_{d}^{i}$ & $500 € /$ order \\
$h_{d}^{i}=H_{r}^{i}$ & $0.05 € /$ item·day \\
$\epsilon^{e}$ & $0.857 \mathrm{~kg} / \mathrm{km}$ \\
$\epsilon^{f}$ & $1.209 \mathrm{~kg} / \mathrm{km}$ \\
\hline
\end{tabular}

\subsection{Pareto fronts analysis}

To help decision-makers negotiate a collaboration, our methods first displays the alternative joint supply networks in the form of Pareto fronts. They can be computed using a preference articulation at the coalition level (Section 4.1) or at the partner level (Section 4.2). To illustrate these methods, the two collaborating companies, with 
similar demand structures, are supposed to have opposite costs-emissions preferences (otherwise the two companies would be very similar, and would easily agree on their joint supply network). One company is focused on costs minimization $\left(\beta_{1}=1\right)$ while its partner is focused on emissions reduction $\left(\beta_{2}=5\right)$.

Figure 6 shows the resulting Pareto fronts for both preference articulations, at the coalition level and at the partner level, as well as the balance of the benefits in augmented cost that the partners get from cooperating (see Section 5.3). We observe that companies first have to decide whether to open 3,4 or 5 DCs. Then, the decisions regarding the locations of these DCs as well as the loading rates of the vehicles will have an additional impact on the costs-emissions balance and on the individual augmented costs. Unsurprisingly, the results obtained with both preference articulations are not drastically different. They rather offer variations and a wider choice of alternative supply networks.

In Figure 6.c, we observe that no solution leads to perfectly equal relative benefits for both companies. This is not exceptional to this instance, and may be an impediment during the negotiation process. In this case, visualizing all possible alternative supply networks (and thus also the non-existing ones), in the form of these Pareto fronts, may definitely be valuable. Interestingly, although collaboration is clearly beneficial for both partners, we see that benefits can vary between $20 \%$ and $29 \%$ for the costfocused company and between $22 \%$ and $27 \%$ for the emissions-focused company. This disparity is a direct consequence of the difference in costs-emissions preferences for both partners. We will elaborate on the impact of individual partner preferences in more detail in the next section.

\subsection{Impact of the individual costs-emissions preferences}

To explore the impact of individual costs-emissions preferences (weight $\beta^{i}$ ), we perform additional experiments in which company 1 is set as a cost-focused company $\left(\beta^{1}=1\right)$ while the partner's preference is altered. First, both companies are similar, being both cost-focused $\left(\beta^{2}=1\right)$. Second, company 2 focuses more on $\mathrm{CO}_{2}$ emissions $\left(\beta^{2}=3\right)$. Third, company 2 is very environmentally conscious $\left(\beta^{2}=5\right)$.

For each scenario, we compare the unique solutions returned by each of the three approaches (six computation methods) introduced in Section 5: the costs-emissions weight $\beta$ can be volume weighted (equation (18), computation method denoted $\beta_{V o l}$ 


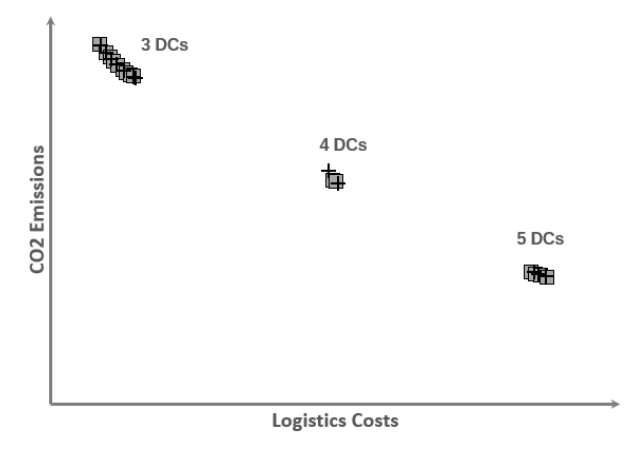

(a) Total coalition costs versus total coalition $\mathrm{CO}_{2}$ emissions.

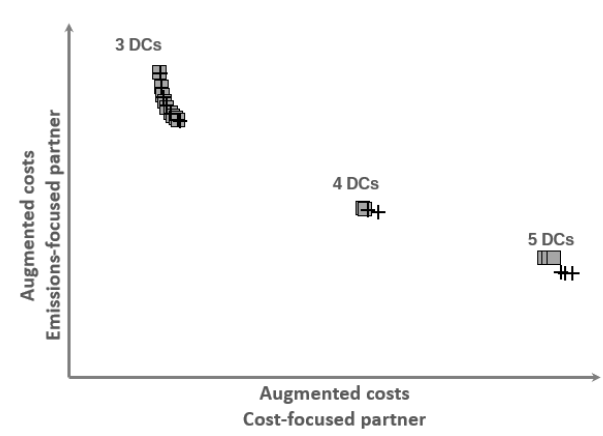

(b) Augmented costs for both partners.

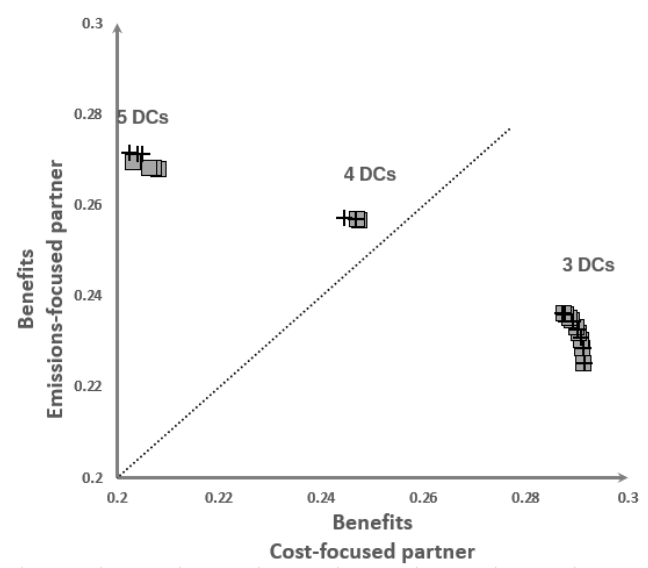

(c) Relative benefits in augmented costs from cooperating, for both partners.

Figure 6.: Pareto fronts obtained using the articulation at the coalition level $(\square)$ and the articulation at the partner level $(+)$ for companies with different costs-emissions preferences. 
in the following) or augmented cost weighted (equation (19), denoted $\beta_{A u g C}$ ); the partner influence weight $\gamma^{i}$ can also be volume weighted (equation (20), denoted $\gamma_{V o l}^{i}$ ) or augmented cost weighted (equation (21), denoted $\gamma_{A u g C}^{i}$ ); the partners benefits can be used as a criterion, maximizing the minimal partner benefit (model (22)-(26), denoted MmBenefit) or minimizing the maximal partner loss (model (27)-(31), denoted $m M L o s s$ ). Note that, for the two last methods (MmBenefit and mMLoss), the shipment size $Q_{d r}$ is computed using equations (17) and (20).

The results are summarized in Figure 7, showing the impact of the costs-emissions preference of the second company on the collaborative benefits for both companies. When the costs-emissions weights are the same for both companies $\left(\beta_{1}=\beta_{2}=1\right.$, first bar for each method), both companies are similar in all respects: cost parameters, demands and preferences. As a consequence, their costs and $\mathrm{CO}_{2}$ emissions reductions from cooperating are very similar. The joint supply network is easily found and the various methods lead to the same results.

With the increase of the second company's weight $\left(\beta_{2}=3\right.$ then 5 , second and third bar for each method), the relative benefit of the collaboration decreases as the companies have to compromise, accounting for different preferences. The cooperative solution becomes more environmentally friendly, with higher vehicle loading rates and in some cases the opening of additional DCs (with $\beta_{2}=5$ and the three methods $\beta_{A u g C}, \gamma_{A u g C}^{i}$ and $M m$ Benefit). Overall, the benefit decreases weakly for company 1 and more severely for company 2 . For the cost-focused company 1 , the decrease in the costs benefit (black bars) is compensated by an increase in the $\mathrm{CO}_{2}$ emissions benefit (grey bars). In other words, the cost-focused company also benefits significantly from the reduction in $\mathrm{CO}_{2}$ emissions enforced by the other partner. The notable exception to that is in the cases where an additional DC is opened to satisfy the emissions-focused company $2\left(\beta_{2}=5\right)$. The benefit for the cost-focused company drops significantly as the additional DC largely increases the cost of the network (and the $\mathrm{CO}_{2}$ emissions reduction does not compensate).

Looking at the second company, for which the costs-emissions weight increases, its benefits are decreasing more severely, deviating more and more from those of its partner. Moreover, the share of profits actually linked to $\mathrm{CO}_{2}$ emissions reductions (grey bars) is decreasing when the costs-emissions weight increases. Although this might seem counter-intuitive, it can easily be explained by the fact that we make use 


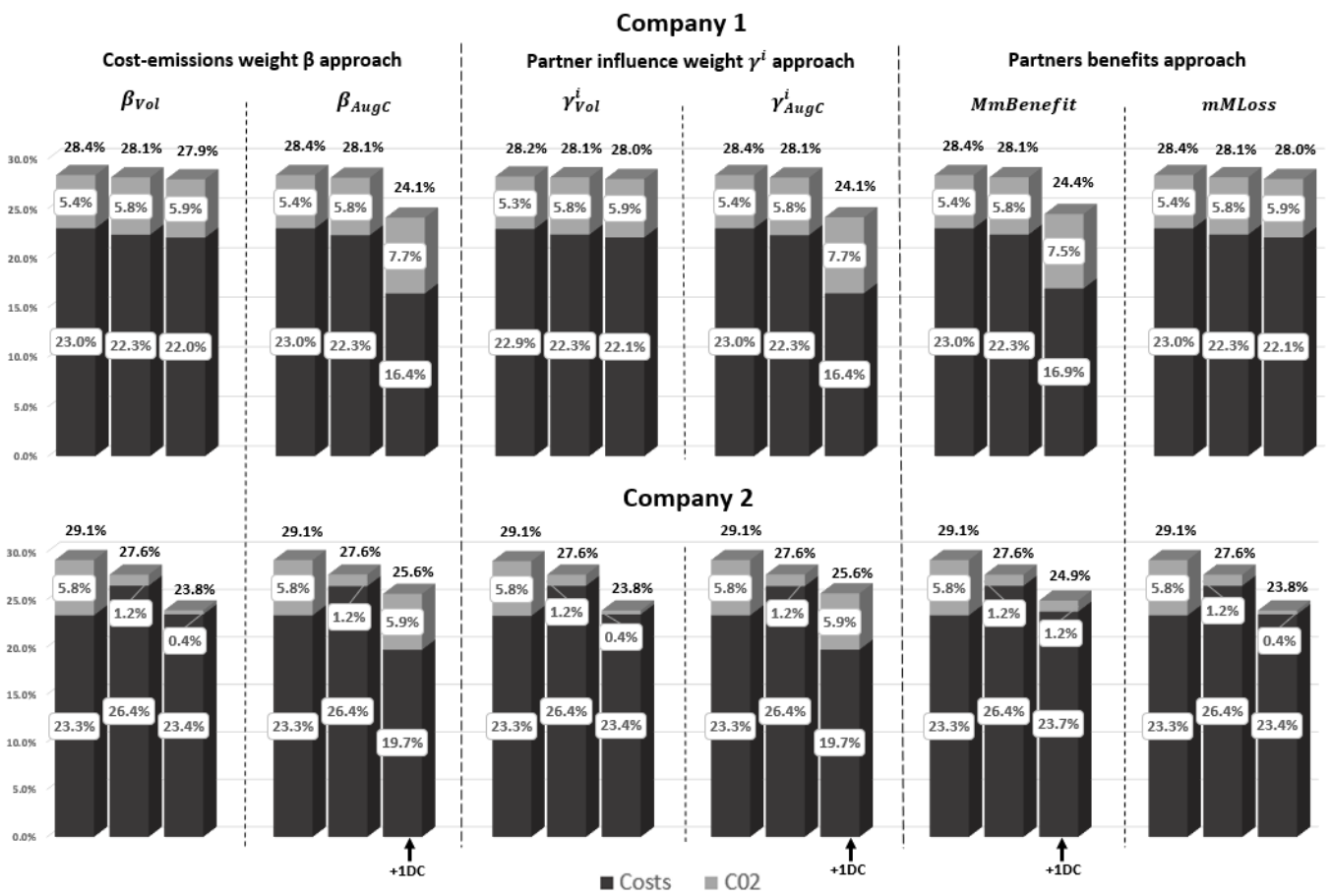

Figure 7.: Relative benefits in augmented cost from cooperating for cost-focused company 1 (first line) and company 2 with a changing costs-emissions preference (second line). Groups of three bars show the benefits obtained by each company when the costs-emissions weight increases for the second company $\left(\beta_{2}=1,3,5\right)$. The weight does not change for company $\left(\beta_{1}=1\right)$. Each group of three bars, in the six columns, is for one the six methods to propose a unique solution. Each bar is decomposed in terms of costs and $\mathrm{CO}_{2}$ emissions reductions.

of stated preference articulation to determine the individual partner preferences. In other words, a company that deems $\mathrm{CO}_{2}$ emissions priority, will already have low $\mathrm{CO}_{2}$ emissions when operating alone. The opportunities for decreasing the emissions even further when collaborating are thus limited, especially if the other partner (company 1 in this case) does not value $\mathrm{CO}_{2}$ emissions reduction. In the special cases where the second company's strong preference for emissions reduction leads to the opening of an additional DC, the emissions indeed drastically decrease, but the benefit is cancelled out by the cost increase.

When the individual costs-emissions preferences differ, and companies become dissimilar, we also see in Figure 7 that the outcomes of the six computation methods of Section 5 diverge. To study this in more detail, we refer to Table 3, which presents, for each method, the benefits in augmented cost obtained in a cooperation between a cost-focused company $1\left(\beta_{1}=1\right)$ and a very environmentally conscious company 2 
$\left(\beta_{2}=5\right)$. To underline the fact that the methods tend to have different strengths and weaknesses, Table 3 shows the benefits of each company, the average benefit revealing the global efficiency of the cooperation, the difference between the benefits unveiling the equity of the cooperation, and the difference with the ideal solution of a company (if it would decide alone for the cooperation). We see that the volume weighted methods $\left(\beta_{V o l}\right.$ and $\left.\gamma_{V o l}^{i}\right)$ lead to solutions with a high average benefit $(25.9 \%)$, in which the cooperation as a whole benefits the most. However, these methods lead to a high disparity between partners (4.1\%), clearly favoring the cost-focused company.

As touched upon earlier, the augmented cost weighted computation methods ( $\beta_{\text {AugC }}$ and $\gamma_{A u g C}^{i}$ ) lead to open an additional DC when the second company is very environmentally conscious $\left(\beta_{2}=5\right)$. In general, these methods favor the emissions-focused company, leading to greener supply networks and larger $\mathrm{CO}_{2}$ emissions reduction. However, as the emissions-focused company tends to have lower profits than its costfocused partner, these methods counterbalance this negative impact, obtaining a lower average for the benefits but a lower gap between augmented costs reductions. In Table 3 , we see that these methods, $\beta_{A u g C}$ and $\gamma_{A u g C}^{i}$, lead to the higher benefit for the emissions-focused company $2(25.6 \%)$, with a low difference with the benefit of company $1(1.5 \%)$.

The method maximizing the minimal partner benefit (MmBenefit) further reduces the difference between the benefits of the partners $(0.5 \%)$. As such, it allows to reach a solution where neither partner feels aggrieved. This is also the method that provides the highest minimum individual benefit (24.4\%). To reach a sufficient benefit for the emissions-focused company 2, an additional DC is opened (as mentioned earlier). The main drawback of this method MmBenefit is that it leads to a degradation of the average global savings level $(24.7 \%)$. In short, MmBenefit is the method giving the most priority to partner equity versus global efficiency. On the opposite, the method minimizing the maximal partner loss ( $m M L$ Loss) leads to very different benefits $(4.2 \%)$ but a more efficient supply network for the cooperation as a whole $(25.9 \%)$. However, it minimizes the gap with the ideal solutions that companies would choose if they could decide alone for the cooperation (3.2\%), and thus disincentivizes the partners to leave the cooperation.

In conclusion, companies which are similar in terms of costs-emissions preferences have higher average benefits, while dissimilar preferences lead to lower and more dis- 
Table 3.: Relative benefits (in \%) in augmented costs from cooperating for cost-focused company $1\left(\beta_{1}=1\right)$ and emissions-focused company $2\left(\beta_{2}=5\right)$, their average and their difference, as well as the highest difference with the ideal cooperative solution of each partner, as found by the six computation methods.

\begin{tabular}{|c|c|c|c|c|c|c|c|}
\hline \multirow[b]{2}{*}{ Method } & \multicolumn{2}{|c|}{ Costs-emissions weight } & \multicolumn{2}{|c|}{ Partner influence weight } & \multicolumn{2}{|c|}{ Partners Benefits } & \multirow[t]{2}{*}{ Average } \\
\hline & $\beta_{V o l}$ & $\beta_{A u g C}$ & $\gamma_{V o l}^{i}$ & $\gamma_{A u g C}^{i}$ & MmBenefit & mMLoss & \\
\hline Benef. Comp. 1 & -27.9 & -24.1 & -28.0 & -24.1 & -24.4 & -28.0 & -26.1 \\
\hline Benef. Comp. 2 & -23.8 & -25.6 & -23.8 & -25.6 & -24.9 & -23.8 & -25.0 \\
\hline Average & -25.9 & -24.8 & -25.9 & -24.8 & -24.7 & -25.9 & -25.3 \\
\hline Difference & 4.1 & 1.5 & 4.2 & 1.5 & 0.5 & 4.2 & 2.7 \\
\hline Highest Diff. Ideal & 3.2 & 4.4 & 3.2 & 4.4 & 4.1 & 3.2 & 3.7 \\
\hline
\end{tabular}

parate benefits. In addition, individual benefits from cooperation are mainly coming from an improvement of the objective which was less favored in the individual case. As such, a cost-focused company collaborating with an emissions-focused company will mainly enjoy significant $\mathrm{CO}_{2}$ emissions reductions. This highlights again the importance of analyzing results (also) at an individual partner level. Finally, the choice of the solution method noticeably impacts the collaborative solution, the characteristics of the joint supply network, its costs and emissions. The various methods could favor a reduction in costs or in $\mathrm{CO}_{2}$ emissions, one partner or the other, the reduction of the augmented cost of the cooperation as a whole or a smaller difference between individual benefits, or even a lower gap with the ideal cooperative solution of each partner.

\subsection{Companies with different sizes}

A significant part of the literature on horizontal cooperation considers coalitions of companies of a similar size (i.e., with similar demand). The reasons put forward to justify this assumption are an easier benefit distribution among partners and the elimination of power influence in the decision-making process (Cruijssen, Bräysy, Dullaert, Fleuren, \& Salomon, 2007; Hacardiaux \& Tancrez, 2019; Vanovermeire, 2014). As our models consider the benefits distribution and the influence weights of the coalition partners, we can use them to analyze the impact on both coalition performance and individual benefits of having partners of different sizes in the coalition. For this, we run a new set of experiments where the first company is twice the size of the second company, while maintaining a similar total demand for the cooperation as previously. The demand rate $\lambda_{r}^{i}$ is computed using the formula in Table 2, with $\pi_{r}$ being the 
Table 4.: Relative benefits (in \%) from cooperating for a large company 1 and a small company 2 , in augmented cost, logistics costs and $\mathrm{CO}_{2}$ emissions, depending on their costs-emissions preferences $\beta^{1}$ and $\beta^{2}$.

\begin{tabular}{l|c|c|c|c|c|c|c|c|c}
\hline & \multicolumn{3}{|c|}{$\beta^{1} / \beta^{2}=3 / 3$} & \multicolumn{4}{c}{$\beta^{1} / \beta^{2}=1 / 5$} & \multicolumn{3}{c}{$\beta^{1} / \beta^{2}=5 / 1$} \\
& Coop. & Large C1 & Small C2 & Coop. & Large C1 & Small C2 & Coop. & Large C1 & Small C2 \\
\hline Augm. costs & $-26.8^{*}$ & -16.8 & -40.5 & $-26.6^{*}$ & -16.5 & -37.6 & $-22.8^{*}$ & -16.2 & -37.1 \\
Logistics costs & -26.5 & -16.3 & -40.3 & -32.3 & -13.0 & -52.3 & -26.3 & -21.5 & -33.9 \\
$\mathrm{CO}_{2}$ emissions & -27.2 & -17.7 & -40.8 & -24.3 & -30.7 & -6.6 & -30.8 & -7.2 & -54.1 \\
\hline
\end{tabular}

*For the partner influence weight and partners benefits approaches, $\beta_{V o l}$ (equation (18)) is used to compute the cooperative augmented cost.

city's population size divided by 750 for the large company 1, and 1500 for the small company 2 (compared to 1000 for both companies previously). Three combinations of individual costs-emissions weights are tested, $\beta^{1} / \beta^{2}=3 / 3,1 / 5$ or $5 / 1$, to illustrate companies with similar $(3 / 3)$ or opposite $(1 / 5$ and $5 / 1)$ costs-emissions preferences. These new instances have been solved with the six computation methods proposed in Section 5, to get unique solutions for the collaboration. Table 4 gives the average results over the six methods, allowing us to focus on the insights related to the cooperation's and companies' benefits.

Looking at Table 4, it directly appears that the relative benefits of both partners are very different, around $16 \%$ in augmented cost for the large company and between $37 \%$ and $40 \%$ for the small company. This is due to the fact that the large partner already has a more effective supply network before cooperating, thanks to better economies of scale. With equal costs-emissions weights $\left(\beta^{1} / \beta^{2}=3 / 3\right)$, the costs and emissions of the large company are only $35 \%$ and $45 \%$ larger, respectively, while its demand volume is twice the volume of the small company. In particular, the average vehicle loading rate for the large company in the stand-alone case is already close to $90 \%$ (for the various costs-emissions weights combinations $\left.\beta^{1} / \beta^{2}\right)$. On the other hand, the small company, when cooperating, gets access to a larger number of DCs (for which they share the costs), better filled trucks (from $79 \%$ in the stand-alone case to around $96 \%$ in the collaborative solutions) and more frequent deliveries (reducing inventory costs). Cooperation is therefore more beneficial, relatively, for the small company than for its larger partner. Companies thus best join forces with larger partners in order to fully exploit cooperation opportunities (as also stated in Verdonck, Ramaekers, Depaire, Caris, and Janssens (2019)).

However, the large company still benefits from a significant reduction of its costs and 
$\mathrm{CO}_{2}$ emissions (around 16\% in augmented cost). Even more, interestingly, the large company is close to reaching the full potential of the collaboration, i.e. the maximum possible benefit, that a company would get deciding alone for the cooperation (for all $\beta^{1} / \beta^{2}$ combinations and with most methods). For example, with costs-emissions weights $\beta^{1} / \beta^{2}=1 / 5$, the results obtained with five of the six computation methods are very similar, with a relative benefit in augmented costs of $17.2 \%$ for the large company ( $37.4 \%$ for the small one), which is very close to its ideal cooperative solution (decided alone) with a benefit of $17.4 \%$. The sixth computation method, which leads to other results, is the augmented cost weighted $\beta_{A u g C}$ method. It favors the small company even more, leading to a benefit of $39 \%$ for the small company and $13.3 \%$ for the large one. The high costs-emissions weight of the small company (artificially) skews the solution to favor it (even opening an additional DC). This $\beta_{\text {AugC }}$ method should thus likely be avoided when companies do not have a demand of similar size.

Further looking at Table 4, the observation provided in Section 6.3 is even stronger with companies of different sizes: when the partners have different costs-emissions preferences, each company benefits most in the non-priority objective. With costsemissions weights $\beta^{1} / \beta^{2}=1 / 5$ for example, the large costs-focused company decreases its $\mathrm{CO}_{2}$ emissions the most (30.7\% vs. $13 \%$ ), while the small emissions-focused company reduces its costs the most $(52.3 \%$ vs. $6.6 \%)$. As a whole, the cooperation reduces its costs by $32.3 \%$ and its emissions by $24.3 \%$, showing that the priority of the larger company for costs still clearly bends the cooperative solution. When both companies have similar sizes (configuration of Section 6.3 and Table $3, \beta^{1} / \beta^{2}=1 / 5$ ), the benefits are more balanced, as the cooperation reduces its costs by $28.6 \%$ and its emissions by $29.3 \%$.

\subsection{Companies with different geographical demand distribution}

In this section, we analyze the impact of the geographical demand distribution of the partners on the collaboration. In these new experiments, we assume that the demand for each company is no longer uniformly spread over all cities (while maintaining a similar total demand for the cooperation as previously). The first company's customers are mostly in the West, while the second company's customers are mostly in the East. Company 1 has $2 / 3^{r d}$ of its demand coming from the 25 most western cities (to the left of the dashed line in Figures 5 and 8 ) and $1 / 3^{r d}$ in the 24 most eastern cities, 
Table 5.: Relative benefits (in \%) from cooperating, for a western company 1 and an eastern company 2 , in augmented cost, logistics costs and $\mathrm{CO}_{2}$ emissions, depending on their costs-emissions preferences $\beta^{1}$ and $\beta^{2}$.

\begin{tabular}{|c|c|c|c|c|c|c|c|c|c|}
\hline & \multicolumn{3}{|c|}{$\beta^{1} / \beta^{2}=3 / 3$} & \multicolumn{3}{|c|}{$\beta^{1} / \beta^{2}=1 / 5$} & \multicolumn{3}{|c|}{$\beta^{1} / \beta^{2}=5 / 1$} \\
\hline & Coop. & West C1 & East C2 & Coop. & West C1 & East C2 & Coop. & West C1 & East C2 \\
\hline Augm. costs & $-26.3^{*}$ & -26.3 & -26.2 & $\mid-22.3^{*}$ & -26.7 & -24.3 & $-24.9 *$ & -24.8 & -23.1 \\
\hline Logistics costs & -30.8 & -31.2 & -30.4 & -30.2 & -24.5 & -35.1 & -26.5 & -32.7 & -19.2 \\
\hline $\mathrm{CO}_{2}$ emissions & -14.7 & -14.8 & -14.7 & -24.9 & -35.9 & -5.2 & -29.2 & -13.0 & -41.1 \\
\hline
\end{tabular}

and vice versa for company 2 . As in the previous section, we consider companies with similar $\left(\beta^{1} / \beta^{2}=3 / 3\right)$ or opposite $\left(\beta^{1} / \beta^{2}=1 / 5\right.$ or $\left.5 / 1\right)$ costs-emissions preferences, and apply the six computation methods to get unique solutions proposed in Section 5 .

Table 5 gives the average benefits for the cooperation and for both companies. As previously, we observe that both companies have significant benefits (between $23 \%$ and $26 \%$ in augmented cost), and that companies benefit more in their non-priority criterion (e.g. emissions for a cost-focused company). Interestingly, Table 5 further shows that the company with higher demand in the west benefits slightly more (around $2 \%$ when preferences are different). The main customers of this company, on the western part of the map, are more spread than those of the second company, which are mainly clustered in the east. As distances are longer to reach western cities, the benefit of cooperation, from more DCs and better vehicle loading rates, is stronger in the west and impacts the western company more strongly, reducing both its logistics costs and its environmental impact. In conclusion, when companies have different geographical demand distributions, companies with a higher demand dispersion obtain higher benefits, as increased geographical coverage provides more cooperation opportunities (in accordance with Cruijssen, Bräysy, et al. (2007), Guajardo and Rönnqvist (2015) and Verdonck et al. (2019)).

Figure 8 shows that the decision process of companies forming a collaboration can strongly impact their collaborative supply network. It is illustrated here for a collaboration between a western cost-focused company and an eastern emissions-focused company. When the western cost-focused company decides alone for the cooperation, only three DCs are opened to achieve lower costs, and their locations are skewed towards the West (see Figure 8.a). When deciding alone, the eastern emissions-focused 
company prefers reducing the $\mathrm{CO}_{2}$ emissions by shortening distances. It thus opens five DCs, of which three are in the East (see Figure 8.b). Besides these two extreme scenarios, it is interesting to look at the methods to identify (realistic) unique solutions proposed in Section 5. In the case illustrated in Figure 8, there is a significant difference between the costs-emissions weight $\beta$ approach on one side and the partner influence weight $\gamma^{i}$ and the partners benefits approaches on the other side. With the partner costs-emissions weights $\beta$ approach, a unique costs-emissions weight $\beta$ is defined for the cooperation and then the supply network is designed, thus not accounting for the difference in costs-emissions preferences $\left(\beta_{i}\right)$ among partners. In Figure 8.c, a weighted average of both $\beta_{i}$ is used to decide to open four DCs evenly spread on the map, i.e. balancing between costs and emissions with similar priority and considering the cooperation as a whole. It leads to an average individual partner benefit of $24.7 \%$. On the opposite, the partner influence weight $\gamma^{i}$ and partners benefits approaches better conserve the individuality of companies, accounting for their different costs-emissions preferences $\left(\beta_{i}\right)$. In Figure 8.d, only three DCs are opened to reduce costs and please the western cost-focused company, but their locations are skewed towards the east (compared to Figure 8.a for example) to shorten distances there and reduce the carbon footprint of the eastern emissions-focused company. The decision thus accounts for both partners' preferences, leading to a higher individual average benefit of $25.9 \%$. In conclusion, when geographical spread and individual preferences differ, companies should prefer applying approaches that conserve these individual preferences as they allow to design a network that has different priorities (costs versus $\mathrm{CO}_{2}$ emissions) in different regions.

\section{Conclusions}

Horizontal collaboration is considered to be a promising avenue in today's demanding markets requiring both efficient and sustainable logistics services. Although supply chain partnerships promise mutual benefits for the participants, those benefits are rarely realized due to differences in partner preferences. Despite its inherent multiobjective nature, the majority of current research considers horizontal logistics collaboration as a single-objective minimization of transportation costs assuming partners agree on a unique collaborative goal. In the best case, the effect of collaboration on 


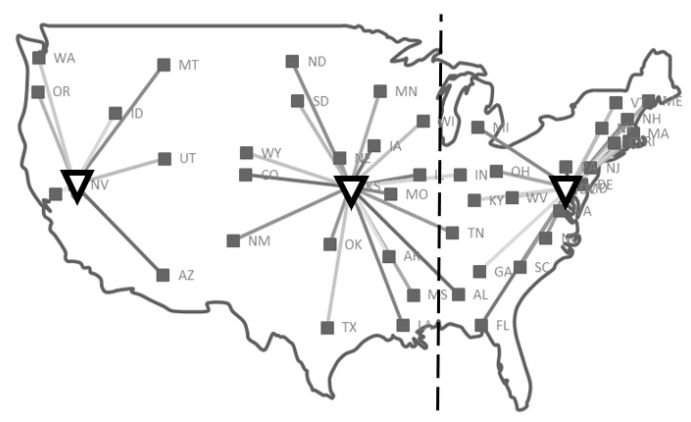

(a)

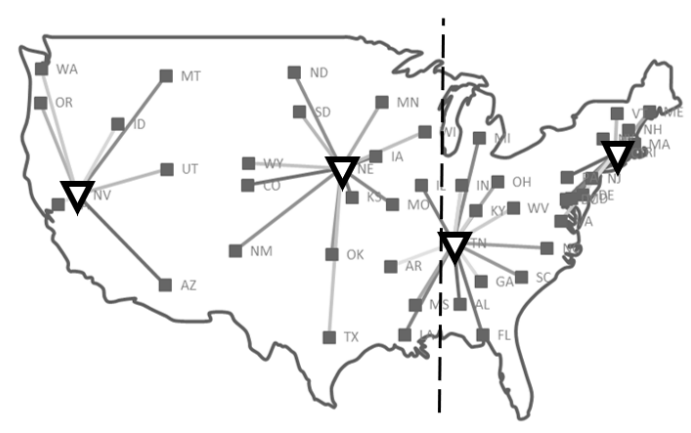

(c)

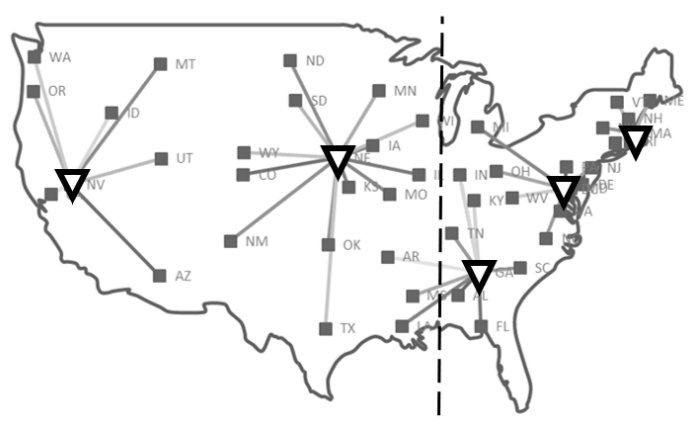

(b)

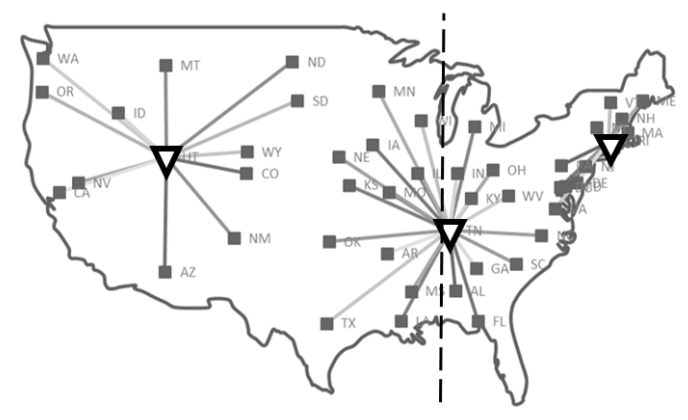

(d)

Figure 8.: Supply networks and DCs locations, for a western cost-focused company 1 and an eastern emissions-focused company $2\left(\beta^{1} / \beta^{2}=1 / 5\right)$, found when the first company decides alone for the cooperation (a), when the second company decides alone (b), with the costs-emissions weight $\beta$ approach (c) and with the partner influence weight $\gamma^{i}$ and partners benefits approaches (d). 
$\mathrm{CO}_{2}$ emissions is computed a posteriori, after costs are minimized. Based on this research gap, the contribution of this paper is twofold. First, we develop a multi-objective framework accounting for the individuality of partners in terms of their costs-emissions preferences and their influence weights. Second, we propose new approaches for solving our multi-objective multi-preference model; two approaches resulting in Pareto fronts and three approaches defining unique solutions. In addition to contributing to academic research field by developing and solving new models, the proposed framework provides quantitative decision support for practitioners implementing and managing horizontal partnerships.

Our multi-objective collaborative location-inventory model, which is formulated as a conic quadratic mixed integer program, accounts for the logistics costs versus $\mathrm{CO}_{2}$ emissions preferences of all partners. Moreover, it directly allocates these costs and emissions to the partners based on efficient proportional rules which are commonly used in practice. In order to solve the model, five solution approaches are proposed. The two first approaches generate sets of Pareto-optimal solutions, providing useful insights regarding the trade-off between costs and emissions for the cooperation on the one hand, and the augmented costs of the different partners on the other hand. While providing multiple solutions aids partners in negotiating on the collaborative strategy, pointing at specific promising solutions is also valuable. Moreover, the complexity of deriving and representing Pareto fronts increases with the number of partners. As such, we propose three additional approaches to identify a unique solution, that would be considered fair and efficient by every partner. The first two approaches compute costs-emissions preference and partner influence weights, while the third approach is based on the individual partner benefits that horizontal cooperation generates. For each of these approaches, two methods are suggested, differing in terms of the way the weights are calculated and the viewpoint on fairness of benefits.

Based on numerical experiments analyzing the performance of the developed solution approaches and the sensitivity of the results to differing instance configurations, the following insights may be formulated. First, collaboration remains beneficial for both partners in all cases, even if their preferences, sizes or geographies are different. Preference weight combinations do, however, impact the individual benefits levels of the partners, with dissimilar weights reducing the potential benefits. Furthermore, when the partners have different costs-emissions preferences, they tend to benefit the 
most in the non-priority objective. Second, the choice of the solution approach impacts the collaborative solution, rewarding either the partnership or a specific partner, favoring a reduction in costs or in emissions, and affecting the gap between individual benefits or with the ideal solution of each partner. Overall, the desirability of the solution reached by each approach depends on the context of the collaboration, the demand characteristics, the partners' preferences and influence. Third, the importance of partner size is confirmed. Comparatively smaller companies will tend to benefit more than larger companies which have better economies of scale when stand-alone. Small companies thus best attract a large partner in order to enjoy savings associated with large joint orders. However, the larger company will still bend the collaboration towards its costs-emissions preference and reach close to its ideal solution. Finally, broad geographical coverage increases the potential benefits of cooperation. When the geographical demand distribution and preferences of the partners are dissimilar, solution approaches accounting for the individual costs-emissions weights should be preferred.

To conclude, the following suggestions for further research can be made. One natural avenue is to include more complex allocation techniques from the literature (e.g. Shapley value) within our optimization framework. Second, the multi-objecive, multipartner approach could be applied to other collaborative settings besides the locationinventory model. According to Pan, Trentesaux, Ballot, and Huang (2019), research on intermodal collaborations should be enhanced, for example. Finally, to further enhance decision support related to partner selection, the sensitivity analysis could be extended to other cooperation configurations.

\section{References}

Atamtürk, A., Berenguer, G., \& Shen, Z.-J. (2012). A conic integer programming approach to stochastic joint location-inventory problems. Operations Research, 60(2), 366-381.

Caramia, M., \& Dell'Olmo, P. (2008). Multi-objective management in freight logistics. Springer-Verlag.

Creemers, S., Woumans, G., Boute, R., \& Beliën, J. (2017). Tri-vizor uses an efficient algorithm to identify collaborative shipping opportunities. Interfaces, 47(3), 244-259.

Cruijssen, F. (2006). Horizontal cooperation in transport and logistics. Thesis, CentER, Tilburg University.

Cruijssen, F., Bräysy, O., Dullaert, W., Fleuren, H., \& Salomon, M. (2007). Joint route 
planning under varying market conditions. International Journal of Physical Distribution \& Logistics Management, 37(4), 287-304.

Cruijssen, F., Cools, M., \& Dullaert, W. (2007). Horizontal cooperation in logistics: opportunities and impediments. Transportation Research Part E: Logistics and Transportation Review, 43(2), 129-142.

Danloup, N., Mirzabeiki, V., Allaoui, H., Goncalves, G., Julien, D., \& Mena, C. (2015). Reducing transportation greenhouse gas emissions with collaborative distribution: a case study. Management Research Review, 38(10), 1049-1067.

Daskin, M. S. (2011). Network and discrete location: models, algorithms, and applications. John Wiley \& Sons.

Daskin, M. S., \& Maass, K. L. (2019). Location analysis and network design. In Operations, logistics and supply chain management (pp. 379-398). Springer.

Deb, K. (2014). Multi-objective optimization. In Search methodologies: Introductory tutorials in optimization and decision support techniques (pp. 403-449). Springer.

Defryn, C., \& Sörensen, K. (2018). Multi-objective optimisation models for the travelling salesman problem with horizontal cooperation. European Journal of Operational Research, 267, 891-903.

Defryn, C., Sörensen, K., \& Dullaert, W. (2019). Integrating partner objectives in horizontal logistics optimisation models. Omega, 82, 1-12.

Ehrgott, M. (2005). Multicriteria optimization. Springer-Verlag.

Farahani, R. Z., Rashidi Bajgan, H., Fahimnia, B., \& Kaviani, M. (2015). Location-inventory problem in supply chains: a modelling review. International Journal of Production Research, 53(12), 3769-3788.

Farahani, R. Z., SteadieSeifi, M., \& Asgari, N. (2010). Multiple criteria facility location problems: A survey. Applied Mathematical Modelling, 34, 1689-1709.

Frisk, M., Göthe-Lundgren, M., Jörnsten, K., \& Rönnqvist, M. (2010). Cost allocation in collaborative forest transportation. European Journal of Operational Research, 205(2), $448-458$.

Gansterer, M., \& Hartl, R. F. (2018). Collaborative vehicle routing: A survey. European Journal of Operational Research, 268(1), 1-12.

Guajardo, M. (2018). Environmental benefits of collaboration and allocation of emissions in road freight transportation. In Sustainable freight transport (pp. 79-98). Springer.

Guajardo, M., \& Rönnqvist, M. (2015). Operations research models for coalition structure in collaborative logistics. European Journal of Operational Research, 240, 147-159.

Guajardo, M., \& Rönnqvist, M. (2016). A review on cost allocation methods in collaborative transportation. International Transactions in Operational Research, 23, 371-392. 
Hacardiaux, T., \& Tancrez, J.-S. (2018). Assessing the benefits of horizontal cooperation using a location-inventory model. (CORE Discussion Paper 2018/14, Université catholique de Louvain.)

Hacardiaux, T., \& Tancrez, J.-S. (2019). Assessing the environmental benefits of horizontal cooperation using a location-inventory model. Central European Journal of Operations Research, 1-25.

Hickman, J., Hassel, D., Joumard, R., Samaras, Z., \& Sorenson, S. (1999). Methodology for calculating transport emissions and energy consumption. TRL report No. PR/SE/491/98.

Hovelaque, V., \& Bironneau, L. (2015). The carbon-constrained eoq model with carbon emission dependent demand. International Journal of Production Economics, 164, 285291.

Jeon, H.-M., Snyder, L. V., \& Shen, Z.-J. M. (2006). A location-inventory model with supply disruptions. In Iie annual conference. proceedings (p. 1).

Jozefowiez, N., Semet, F., \& Talbi, E.-G. (2008). Multi-objective vehicle routing problems. European Journal of Operational Research, 189, 293-309.

Kellner, F., \& Otto, A. (2012). Allocating co 2 emissions to shipments in road freight transportation. Journal of management control, 22(4), 451-479.

Kim, I. Y., \& de Weck, O. L. (2005). Adaptive weighted-sum method for bi-objective optimization: Pareto front generation. Structural and multidisciplinary optimization, 29(2), $149-158$.

Kimms, A., \& Kozeletskyi, I. (2017). Consideration of multiple objectives in horizontal cooperation with an application to transportation planning. IISE Transactions, 49, 11601171.

Leenders, B. P., Velázquez-Martínez, J. C., \& Fransoo, J. C. (2017). Emissions allocation in transportation routes. Transportation Research Part D, 57, 39-51.

Makaci, M., Reaidy, P., Evrard-Samuel, K., Botta-Genoulaz, V., \& Monteiro, T. (2017). Pooled warehouse management: An empirical study. Computers and Industrial Engineering, 112, $526-536$

Marler, R. T., \& Arora, J. S. (2010). The weighted sum method for multi-objective optimization: new insights. Structural and multidisciplinary optimization, 41(6), 853-862.

Melo, M. T., Nickel, S., \& Saldanha-Da-Gama, F. (2009). Facility location and supply chain management-a review. European journal of operational research, 196(2), 401-412.

Moutaoukil, A., Neubert, G., \& Derrouiche, R. (2015). Urban Freight Distribution: The impact of delivery time on sustainability. IFAC-PapersOnLine, 48(3), 2368-2373.

Ouhader, H., \& El Kyal, M. (2017). The impact of horizontal collaboration on $\mathrm{CO}_{2}$ emissions due to road transportation. In Proceedings of the international conference on industrial 
engineering and operations management.

Pan, S., Ballot, E., \& Fontane, F. (2013). The reduction of greenhouse gas emissions from freight transport by pooling supply chains. International Journal of Production Economics, 143(1), 86-94.

Pan, S., Trentesaux, D., Ballot, E., \& Huang, G. Q. (2019). Horizontal collaborative transport: survey of solutions and practical implementation issues. International Journal of Production Research, 57(15-16), 5340-5361.

Saad, R., Rahim, S. A., \& Fernando, Y. (2016). Sustainable green supply chain management and impact on organisations. Journal of Emerging Trends in Economics and Management Sciences, 7(3), 147-155.

Santiváñez, J. A., \& Carlo, H. J. (2018). Reliable capacitated facility location problem with service levels. EURO Journal on Transportation and Logistics, 7(4), 315-341.

Schmeidler, D. (1969). Nucleolus of a characteristic function game. Siam Journal on Applied Mathematics, 17, 1163-1170.

Schuster Puga, M., Minner, S., \& Tancrez, J.-S. (2019). Two-stage supply chain design with safety stock placement decisions. International Journal of Production Economics, 209, $183-193$.

Shen, Z.-J. M., Coullard, C., \& Daskin, M. S. (2003). A joint location-inventory model. Transportation science, 37(1), 40-55.

Soysal, M., Bloemhof-Ruwaard, J. M., Haijema, R., \& van der Vorst, J. G. (2018). Modeling a green inventory routing problem for perishable products with horizontal collaboration. Computers \& Operations Research, 89, 168-182.

Stellingwerf, H. M., Laporte, G., Cruijssen, F. C., Kanellopoulos, A., \& Bloemhof, J. M. (2018). Quantifying the environmental and economic benefits of cooperation: A case study in temperature-controlled food logistics. Transportation Research Part D: Transport and Environment, 65, 178-193.

Tang, X., Lehuédé, F., \& Péton, O. (2016). Location of distribution centers in a multi-period collaborative distribution network. Electronic Notes in Discrete Mathematics, 52, 293-300.

Tsou, C.-S. (2008). Multi-objective inventory planning using mopso and topsis. Expert Systems with Applications, 35, 136-142.

Vanovermeire, C. (2014). Horizontal collaboration in logistics: increasing efficiency through flexibility, gain sharing and collaborative planning (Unpublished doctoral dissertation). University of Antwerp.

Vargas, A., Patel, S., \& Patel, D. (2018). Towards a business model framework to increase collaboration in the freight industry. Logistics, 2(4), 22.

Veldhuizen, D. A. V., \& Lamont, G. B. (2000). Multiobjective evolutionary algorithms: 
Analyzing the state-of-the-art. Evolutionary computation, 8(2), 125-147.

Verdonck, L. (2017). Collaborative logistics from the perspective of freight transport companies (Unpublished doctoral dissertation). Hasselt University.

Verdonck, L., Beullens, P., Caris, A., Ramaekers, K., \& Janssens, G. K. (2016). Analysis of collaborative savings and cost allocation techniques for the cooperative carrier facility location problem. Journal of the Operational Research Society, 67(6), 853-871.

Verdonck, L., Ramaekers, K., Depaire, B., Caris, A., \& Janssens, G. K. (2019). Analysing the effect of partner characteristics on the performance of horizontal carrier collaborations. Networks and Spatial Economics, 19(2), 583-609.

Wang, Y., Zhang, J., Assogba, K., Liu, Y., Xu, M., \& Wang, Y. (2018). Collaboration and transportation resource sharing in multiple centers vehicle routing optimization with delivery and pickup. Knowledge-Based Systems, 160, 296-310.

Zolezzi, J. M., \& Rudnick, H. (2002). Transmission cost allocation by cooperative games and coalition formation. IEEE Transactions on power systems, 17(4), 1008-1015. 